\title{
Composiçào do zooplâncton em cinco lagos da Amazônia Central
}

\author{
Elsa Rodrigues Hardy (")
}

\begin{abstract}
Resumo
O estudo da composição, "standing-stock" e da diversidade do zooplancton constituido por Rotifera, Cladocera e Copepoda foi realizado em cinco lagos da Amazônia Central. Estes lagos possuem caracteristicas físicas, químicas e biológicas distintas, o que permite colocá-los em dois grupos: 1 . lagos que apresentam maiores concentraçōes iônicas, maior disponibilidade de nutrientes e maior diversidade de espécies zooplanctônicas; 2. lagos, com baixa concentração de ions, poucos nutrientes e pequena diversidade de espécies zooplanctônicas. Os lagos colocados no primeiro grupo são os da "várzea" (Castanho, Redondo e Jacaretinga); no segundo grupo, ficam o Cristalino e Tarumã-mirim (lagos de terra firme). A estrutura da comunidade zooplanctônica, nos lagos da Amazônia, é periodicamente alterada pelas inundaçōes dos rios.
\end{abstract}

\section{INTRODUÇÃo}

O zooplâncton de água doce é dominado, principalmente, pelos Rotifera, Cladocera e Copepoda.

Segundo Pennak (1957), a maior parte das comunidades limnéticas é caracterizada por apresentar, em cada grupo, uma espécie excepcionalmente abundante e numericamente dominante sobre as outras, sendo que, abundância e tempo de ocorrência, de cada espécie, varia de lago para lago. Essa dominância de uma espécie está associada, provavelmente, a certas características genéticas, morfológicas, fisiológicas e ecológicas, que a capacitam a utilizar seu habitat mais eficientemente e com maiores vantagens sobre as outras espécies.

Os trabalhos de Matsumura-Tundisi et al 1976; Rocha \& Matsumura-Tundisi, 1976, realizados na Represa do Lobo (São Carlos, São Paulo-Brasil), mostraram a existência de cerca de quinze espécies de rotíferos, dez de cladóceros e treze de copépodos, havendo, sempre, uma dominante, para cada grupo.
A composição de qualquer comunidade ecológica sofre constantes mudanças, devido à produção de novos organismos, crescimento dos indivíduos e transformações de um estágio de vida para outro, mortes, movimentos locais e migrações. Cada membro da espécie exibe freqüentes flutuaçōes, de maior ou menor amplitude, na sua densidade populacional e na sua atividade individual.

Embora exista grande interdependência entre os membros das espécies que compōem uma comunidade, e que as flutuações na densidade populacional sejam controladas direta ou indiretamente pelos mesmos fatores ambientais, cada espécie difere, grandemente, de outras quanto ao ciclo de vida, comportamento e respostas aos vários fatores ambientais (Dice, 1968).

Como resultado das diferenças apresentadas pelos vários membros das espécies quanto aos períodos de atividade e padrão de flutuação, na densidade populacional, toda comunidade pode variar de hora em hora, de dia para dia, de estação para estação ou de ano para ano. Tais mudanças na composição da comunidade, pode, às vezes diminuir abundância re. lativa de certos membros da espécie, porém outros são melhor sucedidos, passando a do minar a comunidade, resultando importantes mudanças na sua estrutura.

As comunidades planctônicas, tanto de água doce como marinha, freqüentemente apre. sentam mudanças periódicas na sua composi Ção. É conhecido que estas mudanças são profundas, alterando, geraimente, os caracteres de comunidades particulares. Além disso, tem sido observado que algumas dessas flutuaçōes são cíclicas e outras, estão correlacionadas com mudanças periódicas, no ambiente físico, através de alternações de dia para noite, de estação para estação e de períodos úmidos pa-

(") - Instituto Nacional de Pesquisas da Amazônia, Manaus. 
ra secos. As causas precisas da maior parte de todas essas mudanças que as comunidades sofrem, são ainda desconhecidas.

Os estudos de Green (1965, 1972a,b, 1976; Burgis, 1973), realizados nos lagos da África, mostraram os prováveis fatores que estariam influenciando, na mudança da composição das espécies. A eutroficação dos lagos pela atividade humana seria o principal responsável pelo desaparecimento de algumas espécies de Cladocera nos lagos Mutanda, Bunyony e Mulehe (Uganda) segundo Green (1976). Burgis (1973), entretanto, considera a predação como fator responsável pela mudança da composiçăo do zooplancton do lago George.

$\mathrm{Na}$ Amazônia, foram realizados alguns estudos sobre a composição da comunidade zooplanctônica. Dentre eles, destacam-se os de Koste $(1972,1974)$ e Schaden (1976), que estudaram a composição dos rotíferos sob o aspecto taxonômico e de composição; Cipolli \& Carvalho (1973) realizaram estudos de ocorrência de Calanoida e Cyclopoida das águas da região do Guamá, Capim e Tocantins; Brandorff (1977) que realizou estudo da dinâmica de população de crustáceos zooplanctônicos no lago Castanho.

Esses autores, porém, trataram os problemas da comunidade zooplanctônica, em termos de grupos, isoladamente, ou considerando apenas um tipo de lago, o que torna difíci! estabelecer as diferenças encontradas na composição da comunidade zooplanctônica, com os di. ferentes tipos de lagos.

Quanto ao uso do índice de diversidade, para interpretar a estrutura da comunidade de um ecossistema, ou mesmo para relacionar com a trofia dos lagos, Margalef (1974) trabaIhando com organismos fitoplanctônicos, fornece valores inferiores a 1,0 em lagos eutróficos e o máximo de 5,0 em lagos oligotróficos e distróficos. Com relação ao zooplancton, o autor cita apenas os índices mais freqüentes que estăo entre 1,5 e 4,0, sem contudo, relacionar com a trofia dos lagos.

No presente trabalho, foram calculados índices de diversidade para alguns grupos do zooplancton, na tentativa de estabelecer algu- ma relação com os tipos de lagos encontrados na Amazônia, tal como, a encontrada por Margalef (lbid.) em comunidades fitoplanctônicas.

\section{DEscrição dos LAgos ESTUdAdOS}

Os corpos de água formados pelos rios da região Amazônica, nos períodos de enchentes e vazantes, são designados como lagos, por apresentarem as características de um sistema lêntico, normalmente rasos, sem correntes, onde se desenvolvem comunidades produtoras, consumidoras e decompositoras, típicas dos verdadeiros lagos e reservatórios.

Cinco lagos foram escolhidos para este estudo, todos localizados na Amazônia Central, perto da cidade de Manaus. Três da "várzea" do rio Solimões e dois de "terra firme", no rio Negro. A localização de todos se encontra nas Fig. 1, 2 e 3.

Os lagos do Castanho, Jacaretinga e Redondo são denominados lagos de várzea e conservam uma ligação com o rio, através de furos e canais que os alimentam. Exceto o Castanho que está conectado com o rio Amazonas, durante o ano todo, os lagos Redondo e Jacaretinga são alimentados pelo rio, somente nas grandes enchentes, ficando isolados durante a estação seca, quando adquirem quase total autonomia; portanto, podem estar sujeitos a consideráveis mudanças nas suas características físicas, químicas e biológicas, nas grandes flutuações do nivel da água.

$\mathrm{O}$ lago do Castanho dista cerca de $50 \mathrm{~km}$ a sudoeste de Manaus, à margem direita do rio Solimōes, ao qual está conectado através de um canal, o paraná do Janauacá. Esta ligação entre o paraná e o lago é que determina suas reais dimensões, podendo oscilar muito na sua área e profundidade, dependendo do nível do rio. Sua área está estimada entre 1,5 a 2,0 $\mathrm{km}^{2}$ (Schmidt, 1973) e sua profundidade máxima atingiu $3,60 \mathrm{~m}$ em fevereiro e, em julho. $9,50 \mathrm{~m}$.

O lago Redondo é típico lago de várzea, distante da cidade de Manaus cerca de $25 \mathrm{~km}$ a sudoeste. Pertence a um conjunto de lagos, formados na várzea do paraná do Careiro. É pequeno, medindo 860 metros de comprimento 


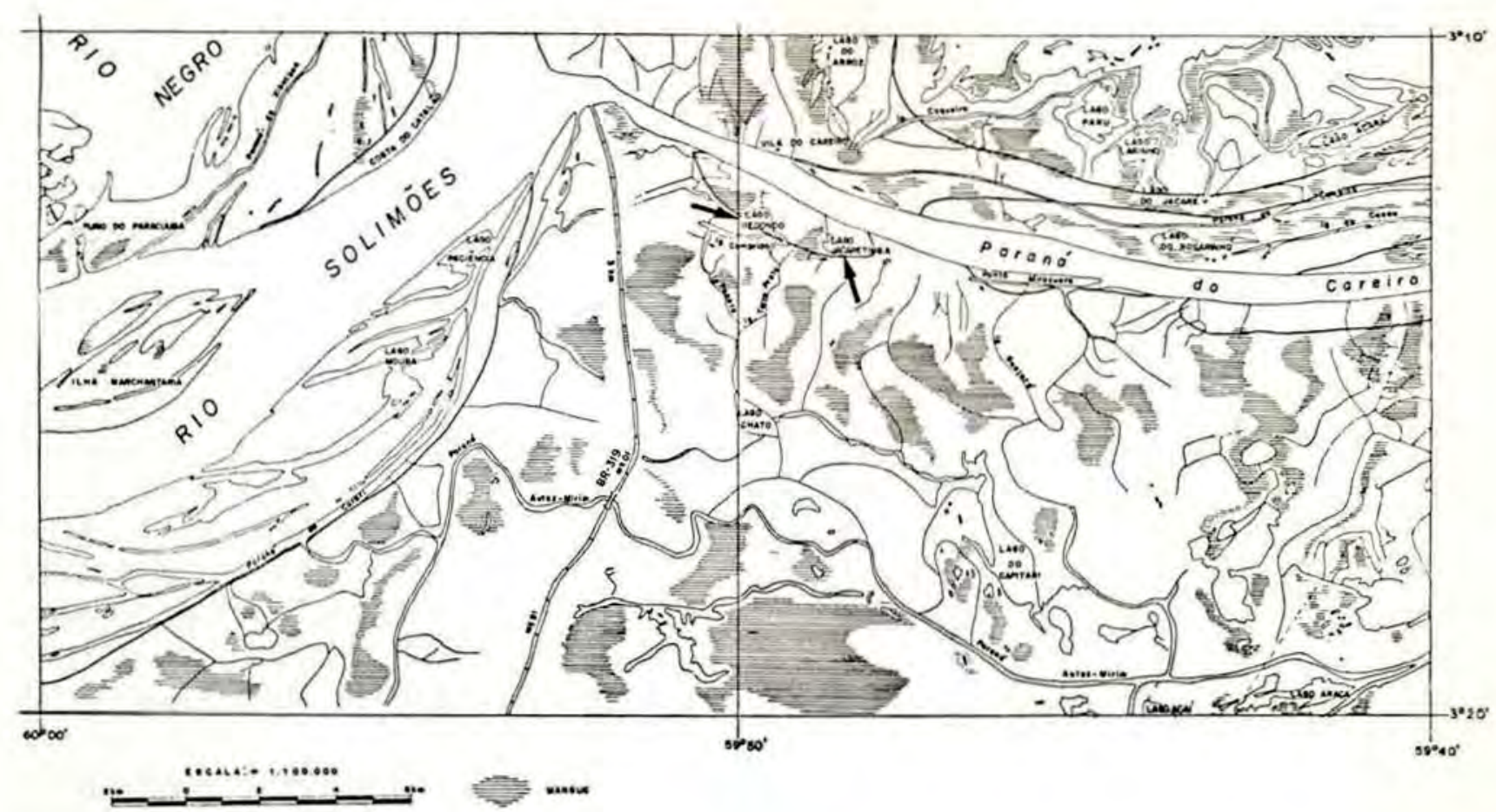

Fig. 1 - Localização dos lagos da várzea, na Amazônia Central. (Ampliado do mapa do Dep. Nac. da Prod. Mineral).

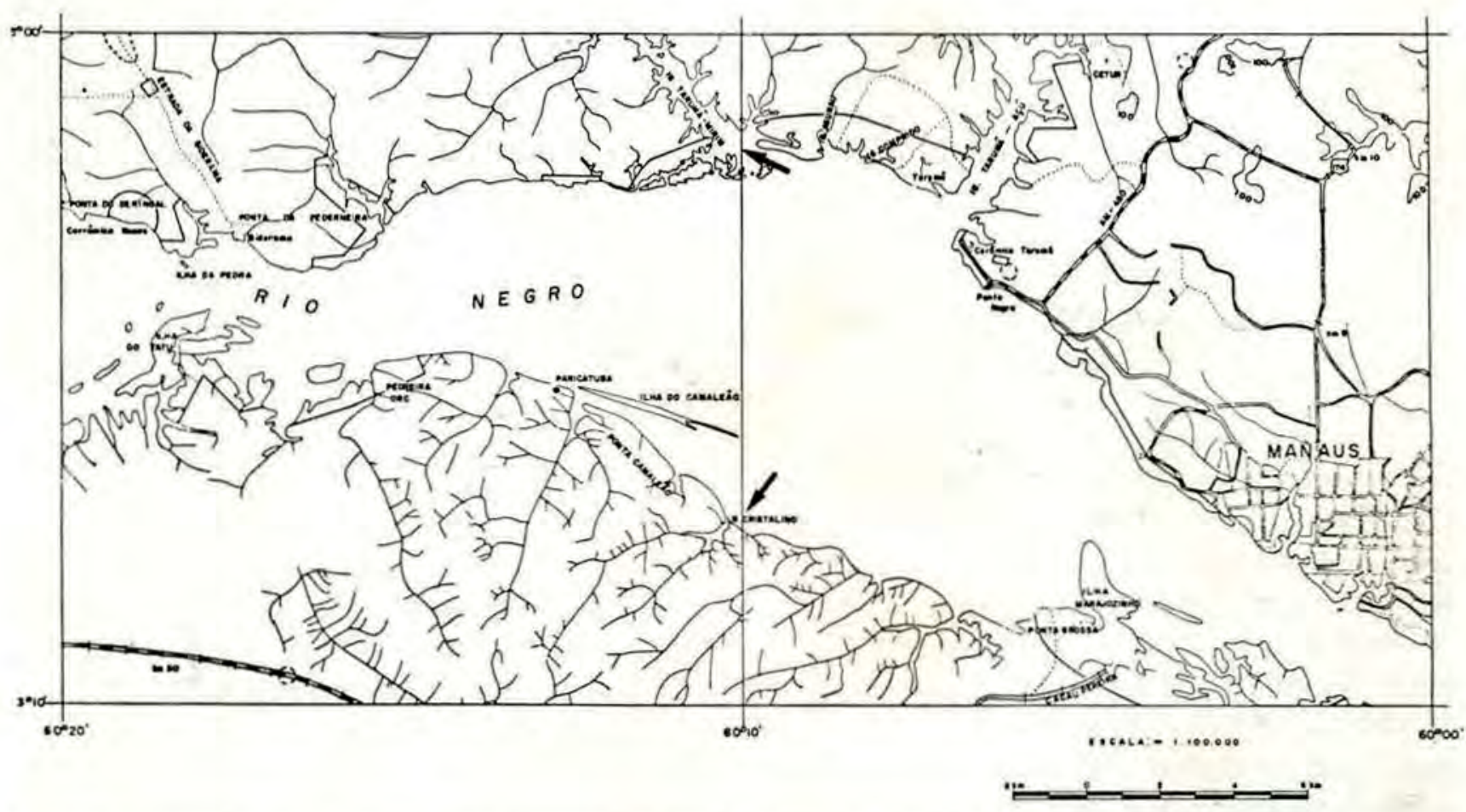

Fig. 2 - Localização dos lagos às margens do rio Negro. (Ampliado do mapa do Dep. Nac. da Prod. Mineral). 


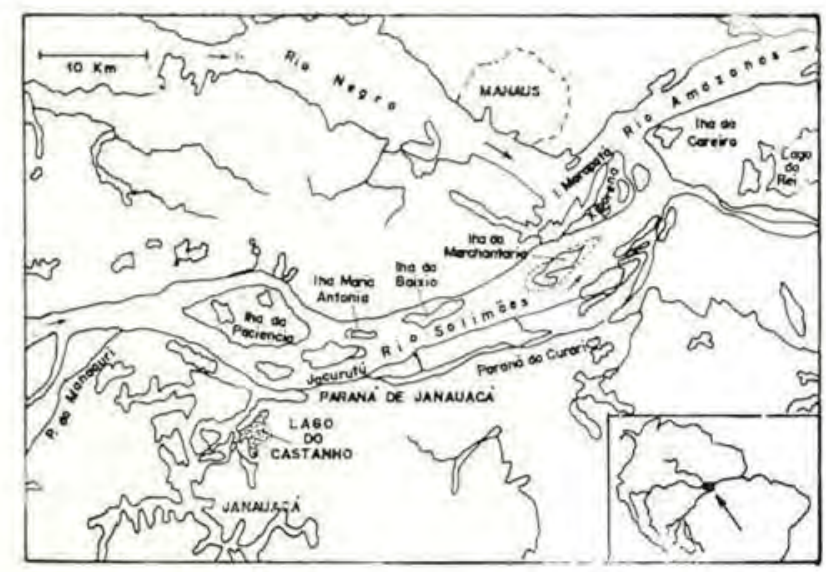

Fig. 3-Localização do lago Castanho nas margens do rio Solimōes (De Schmidt, 1973).

e $523 \mathrm{~m}$ de largura Marlier (1965), apresentando profundidade mínima de $\pm 1,0$ e máxima de $4,0 \mathrm{~m}$. Recebe, periodicamente, águas do rio Solimōes nas grandes enchentes. Possui, na sua região litorânea, grande variedade de plantas aquáticas (Ibid.).

O lago Jacaretinga está situado no paraná do Careiro, perto de Manaus, medindo cerca de 600 metros de comprimento e 300 metros de largura (Santos, 1978). É lago de várzea, influenciado fortemente pelas inundações do rio Solimōes, cujas águas penetram, através de um estreito canal artificial, fazendo com que o nível da água se eleve, temporariamente, no lago. É pouco profundo, medindo geralmente 0,90 a $6,0 \mathrm{~m}$.

Os lagos Tarumã-Mirim e Cristalino são denominados de água preta, pela forte influência que recebem das águas do rio Negro, possuindo mesmo caracteristicas físicas e quimicas similares às encontradas nas águas do rio. São mais profundos que os lagos de várzea.

O lago Tarumã-Mirim situa-se perto da cidade de Manaus (cerca de $20 \mathrm{~km}$ ) na margem esquerda do rio Negro. Apresenta profundidade moderada, de $7,5 \mathrm{~m}$ a $11 \mathrm{~m}$. Está conectado com o rio durante todo o ano. É um típico "lago de ria", de forma dendritica.

O lago Cristalino localiza-se à margem direita do rio Negro, a $20 \mathrm{~km}$ de Manaus. É pequeno, medindo cerca de $700 \mathrm{~m}$ de comprimento e $200 \mathrm{~m}$ de largura de águas transparen- tes com moderada profundidade, apresentando, em fevereiro, 4,0 m no meio do lago e 8,0 $\mathrm{m}$, em julho. Sofre influência das águas do rio Negro, nas grandes enchentes, mas fica isolado, durante as vazantes, limitado com o rio. por uma típica floresta de "campina".

\section{METODOLOGLA}

LOCAL E ÉPOCA DAS COLETAS

O material para estudo foi obtido, em duas épocas: uma, em fevereiro de 1977, caracterizada por forte precipitaçãc em torno de $225.0 \mathrm{~mm}$, temperatura média de $24,8^{\circ} \mathrm{C}$, umidade relativa, em torno de $93,2 \%$; outra, em julho de 1977, caracterizada por pouca precipitação. cerca de $79,9 \mathrm{~mm}$, temperatura em elevação com $26,3^{\circ} \mathrm{C}$ e umidade relativa em torno de $82,6 \%$.

Para cada lago escolhido, foram fixadas certas estações que diferiram de lago para lago. Sua escolha foi feita, baseando-se, principalmente, nas prováveis diferenças biológicas que poderiam ser encontradas, nos diversos pontos do lago, face às condições por ele apresentadas. As macrófitas aquáticas foram geralmente, um ponto de referência para escoIha das estações, para os lagos de "várzea".

\section{PARÂMETROS CLIMATOLÓGICOS}

Foram fornecidos pelo Setor de Meteorologia do Instituto Nacional de Pesquisas da Amazônia (INPA), os seguintes parâmetros climatológicos: precipitação, umidade relativa do ar e temperatura, coletados na Estação Meteorológica, localizada na Reserva Ducke, km 26 da Rodovia Manaus-Itacoatiara.

\section{PARÂMETROS FÍSICOS E QUíMICOS}

Nivel da água - Os dados do nível do rio Negro, no porto de Manaus, sobre o nível do mar, foram fornecidos pela "Manaus Harbour". As medidas foram feitas diariamente e as oscilações das águas do rio dadas $\mathrm{em} \mathrm{cm}$.

Temperatura da água - Foi utilizado um termístor tipo TOHODENTAN, modelo ET3. Em todos os lagos, a temperatura $\mathrm{em}{ }^{\circ} \mathrm{C}$ foi medida de metro em metro, desde a superfície até o fundo. 
Oxigênio dissolvido - $\mathrm{A}$ determinação do oxigênio dissolvido dado em $\mathrm{mg} / \mathrm{l}$ foi feita pelo método de Winkler, descrito no "Manual for Chemical Analysis of Freshwater" (Goltermand, 1969). Foi utilizada para coleta de água, uma garrafa do tipo Ruttner com capacidade de 1 litro. As amostras de água foram fixadas. imediatamente após cada coleta e as determinações feitas no laboratório de Hidroquímica do INPA. De modo geral, em todos os lagos os dados de oxigênio dissolvido foram obtidos, nas camadas de superfície e do fundo, cuja profundidade variou de estação para estação.

pH - Foi determinado no laboratório de Hidroquímica do INPA, logo após a coleta, utilizando-se um pHmetro portátil.

Condutividade - A condutância específica das amostras foi medida com um condutômetro do tipo $E_{52}$ em $\mathrm{us}_{25} / \mathrm{cm}$.

Nutrientes - Foram determinados os seguintes nutrientes: fósforo total, nitrato e silicato reativo. As amostras de água foram coletadas com garrafa do tipo Ruttner e acondicionadas em frascos de polietileno, sendo congeladas, para posterior análise.

Fósforo total - Foi determinado através de espectrofotometria segundo Strickland \& Parsons (1965).

Nitrato - Foi determinado por espectrofotometria de acordo com a técnica descrita em Strickland \& Parsons (Ibid.), que consiste na determinação de $\mathrm{NO}_{3}$ pela redução a $\mathrm{NO}_{2}$. Foi utilizada uma coluna redutora de cádmio, "Redutor Jonee", compreendendo um tubo de vidro de $40 \mathrm{~cm}$ de comprimento e $9 \mathrm{~mm}$ de diâmetro interno com capacidade de $50 \mathrm{ml}$ (Grasshoff, 1964).

Silicato - Foi determinado pelo método espectrofotométrico, segundo Goltermann (1969).

fons - Foram determinados os seguintes ions de $\mathrm{Mg}^{++}, \mathrm{Mn}^{++}, \mathrm{Na}^{+}, \mathrm{Zn}^{++}, \mathrm{K}^{+}$, através do espectrofotômetro de absorção atômica do tipo PERKIN ELMER 306.

PARÂMETROS BIOLÓGICOS

Análise da composição de zocplancton, nos diferentes lagos - Para análise do zoo- plancton, foram coletados 60 litros de água com uma bomba de sucção, manual. Em cada estação, foram obtidas amostras da superfície e do fundo que foram concentradas, filtrandose numa rede de nylon de $36 \mu \mathrm{m}$. O material biológico foi fixado em formol a $4 \%$, e análises posteriores foram realizadas no laboratório com auxilio de uma lupa e de um micros. cópio de câmara clara, utilizando-se, geralmente, aumentos de $200 \mathrm{X}$ e $400 \mathrm{X}$. Os organismos foram identificados, na maioria dos casos, até a espécie, baseando-se nas descrições dos seguintes autores: Herbst (1967), Goulden (1969), Brandorff (1972, 1973, 1976), Harding (1957), Richard (1897), Sars (1901), Daday (1902), Marsh (1913), Thomasson (1953), Olivier (1962), Pennak (1953), Schaden (1976), Koste (1972), Edmondson (1959). Algumas foram desenhadas com auxílio da câmara clara e são apresentadas no anexo, juntamente com as figuras das espécies, ilustradas por outros autores.

"Standing-stock" e distribuição de zooplancton - Para obtenção do "standing-stock" foram feitas contagens dos organismos da amostra total, sendo que, ocasionalmente, também subamostragens quando ocorreu grande quantidade em número de individuos por $\mathrm{m}^{3}$.

Indice de diversidade de espécie e equitatividade - A diversidade de espécies é um dos conceitos básicos e tem sido usada para caracterizar comunidades e ecossistemas. O índice de diversidade de espécies, mais recente e amplamente usado é a fórmula de "Shannon's Information Theory of Communication" (Shannon \& Weaver, 1949), dada por $H_{(s)}=-\sum_{i=1}^{s} p r \log _{2} p r$ onde, s é o número total de espécies na amostra, e pr a proporçãc entre o número de indivíduos de cada espécie. em relação ao número total de espécies presentes. A unidade é bits/indivíduo.

A equitatividade pode ser calculada, numericamente, usando-se várias fórmulas. Para este estudo usou-se $E=H^{\prime} / H_{\max }$ (Pielou, 1966), onde $H^{\prime}$ é a diversidade de espécies obtida pela fórmula de Shannon-Weaver; $H_{\max }$ é a diversidade de espécies sob condiçōes de máxima equitatividade; $\mathrm{E}$ é o valor de equita- 
tividade que vai de $0-1.0 ; \mathrm{H}_{\max }$ é calculado. tomando-se o logaritmo natural do número de espécies na amostra.

Para obtençăo do índice de diversidade de espécie, foram contadas as amostras de cada lago, sendo os organismos, geralmente identificados, até à espécie. Para este estudo, foram considerados somente os grupos zooplanctônicos, constituídos pelos Cladocera e Rotifera.

Indice de similaridade - Os cinco lagos estudados, foram comparados por meio do índice de similaridade de Sorensen (1948), aplicando-se a seguinte equação: $S=\frac{2 c}{a+b} \times 100$ onde $c$ é o número de espécies comuns às comunidades $a$ e $b$, a é o número de espécies presentes na primeira comunidade; e $b$ é o número de espécies presentes, na segunda comunidade. O coeficiente é igual a 100 quando duas comunidades são compostas pelas mesmas espécies; é igual a zero quando duas comunidades têm espécies inteiramente diferentes. Cada par de lagos obteve o valor numérico correspondente ao número de espécies coexistindo.

\section{Resultados}

\section{ANÁLISE DOS PARÂMETROS CLIMATOLÓGICOS}

Precipitação total e nível do rio - $\mathrm{A}$ área de Manaus apresenta alta pluviosidade. sendo que a precipitação total, obtida no ano em estudo, fol de $2.268,9 \mathrm{~mm}$. Junho, julho e agosto foram meses de baixa pluviosidade $(100 \mathrm{~mm})$. Nos outros meses, apresentaram valores maiores que $100 \mathrm{~mm}$, sendo que os máximos foram atingidos em março e abril, respectivamente, com 381,8 e $391,2 \mathrm{~mm}$.

Nos dois períodos de coleta (fevereiro e julho), a precipitação mensal foi 225,2 e 79,9 $\mathrm{mm}$, respectivamente.

A flutuação do nível dos rios da Região Amazônica não se encontra diretamente relacionada com os períodos de alta e baixa pluviosidade, como mostra a figura 4. O degelo dos Andes é o fator primordial que contribui para o aumento do volume d'água (Junk, 1973).

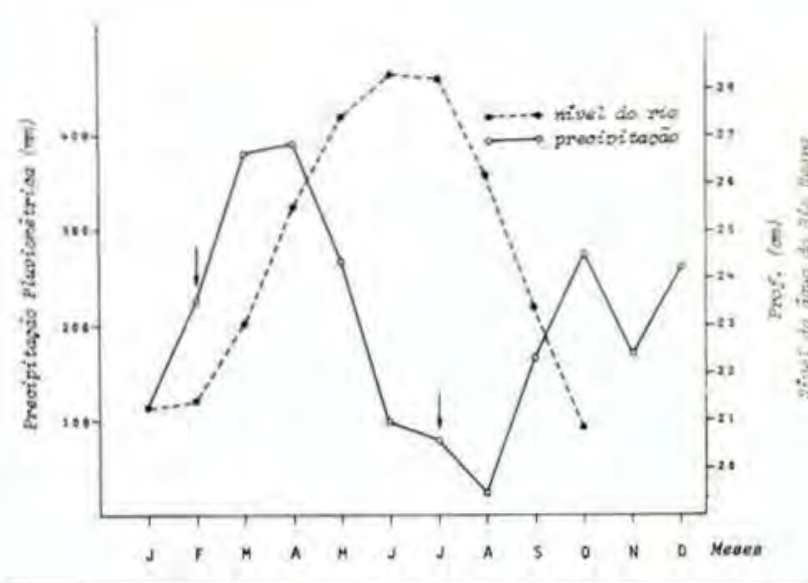

Fig. 4 - Relação entre a precipitaçâo média mensal na cidade de Manaus e o nível da água do rio Negro. As setas indicam os períodos de coleta.

Os períodos de cheias e vazantes são irregulares. De modo geral, o nível da água atinge o máximo em junho, julho e agosto e o nível mínimo de outubro a janeiro.

$\mathrm{Na}$ tabela I, estão apresentados os valores de profundidade obtidos, nas diversas estaçōes dos lagos Castanho, Jacaretinga, Cristalino e Tarumā-mirim, nos meses de fevereiro e julho. Para o lago Redondo estāo apresentados somente os valores do mês de julho.

$\mathrm{Em}$ todos os lagos, observa-se aumento considerável de profundidade, no mês de julho correspondendo ao período de nível máximo do rio.

Umidade relativa e temperatura do ar A tabela II registra as médias mensais de umidade relativa e temperatura do ar.

Os valores médios de umidade relativa variam, muito pouco, verificando-se durante o ano, elevada porcentagem de umidade. Os valores extremos foram de 93,2 e $79,4 \%$ respectivamente, nos meses de fevereiro e agosto.

Quanto à temperatura do $\mathrm{ar}$, no mês de fevereiro, registrou-se a mínima de $24,8^{\circ} \mathrm{C}$. Em junho e agosto, os meses mais quentes, houve temperatura média de 26,3 e $27,3^{\circ} \mathrm{C}$.

ANÁLISE DOS PARÂMETROS FÍSICOS E QUÍMICOS DOS LAGOS ESTUDADOS

Lago Redondo - Neste lago, os parâmetros físicos e químicos foram medidos só no mês de julho. 
YABELA I - Dados de profundidade em metros $(\mathrm{m})$ dos lagos Redondo, Castanho, Jacaretinga, Cristalino $e$ Taru. naá-Mirim, nas várias Estaçōes.

\begin{tabular}{|c|c|c|c|c|c|c|c|c|c|c|}
\hline \multirow{3}{*}{ Estaçöes } & \multicolumn{10}{|c|}{ L A GOS } \\
\hline & \multicolumn{2}{|c|}{ REDONDO } & \multicolumn{2}{|c|}{ CASTANHO } & \multicolumn{2}{|c|}{ JACARETINGA } & \multicolumn{2}{|c|}{ CRISTALINO } & \multicolumn{2}{|c|}{ TARUMÃ-MIRIM } \\
\hline & Fevereiro & Julho & Fevereiro & Julho & Fevereiro & Julho & Fevereiro & Julho & Fevereiro & Julhn \\
\hline 1 & - & 4.0 & 3.60 & 10.0 & 0.70 & 5.0 & 5.0 & 7.0 & 8.0 & 11.0 \\
\hline 11 & - & 10 & 3.60 & 9.5 & 0.90 & 4.5 & 2.10 & 5.0 & 6.0 & 11.0 \\
\hline 111 & & & & & 2.0 & 5.0 & 1.50 & 7.0 & & \\
\hline IV & & & & & 1.70 & 6.0 & & & & \\
\hline
\end{tabular}

TABELA II - Dados de temperatura do ar (Valores médios) e umidade relativa do ar (Valores médios) na cidade de Manaus.

\begin{tabular}{l|c|c}
\hline \multicolumn{1}{c|}{ Meses } & $\begin{array}{c}\text { Temperatura } \\
\text { do ar } \% \text { C }\end{array}$ & $\begin{array}{c}\text { Umidade } \\
\text { relativa \% }\end{array}$ \\
\hline Janeiro & 26.1 & 86.8 \\
Fevereiro & 24.8 & 93.2 \\
Março & 24.9 & 91.9 \\
Abril & 25.2 & 89.8 \\
Maio & 24.9 & 89.8 \\
Junho & 24.6 & 89.3 \\
Julho & 26.3 & 82.6 \\
Agosto & 27.3 & 79.4 \\
Setembro & 26.3 & 86.0 \\
Outubro & 25.3 & 89.6 \\
Novembro & 25.8 & 85.3 \\
Dezembro & 24.9 & 88.4 \\
\hline
\end{tabular}

Temperatura - Na estação I, onde a pro. fundidade local foi de $4.0 \mathrm{~m}$, observou-se uma distribuição vertical de temperatura uniforme, a partir de $1.0 \mathrm{~m}$, havendo pequena variação de cerca de $0,5^{\circ} \mathrm{C}$ entre superfície $(0.0 \mathrm{~m})$ e 1.0 de profundidade. A estaçăo II, com profundidade de $1.0 \mathrm{~m}$, apresentou variação maior $\left(1,4^{\circ} \mathrm{C}\right)$ entre a superfície $(0.0 \mathrm{~m})$ e o fundo (1.0m).

Oxigênio dissolvido, $\mathrm{pH}$ e condutividade - Na tabela III estão apresentados os valores de oxigênio dissolvido, $\mathrm{pH}$ e condutividade.

Não foi observada nenhuma variação, no teor de oxigênio dissolvido, entre as duas estações. A maior concentração se verificou na estação II, com o valor de $4.0 \mathrm{mg} / \mathrm{l}$.

TABELA III - Dados de oxigênio dissolvido $(\mathrm{mg} / \ell)$, pH e condutividade $(\mu \mathrm{s} / \mathrm{cm})$ nas estaçőes I e II do lago Redondo obtidos no mês de julho

\begin{tabular}{|c|c|c|c|c|c|c|c|}
\hline \multirow{3}{*}{ Estaçōes } & \multirow{3}{*}{ Prof. } & \multirow{2}{*}{\multicolumn{2}{|c|}{$\begin{array}{c}\mathrm{O}_{2} \text { DISSOLVIDO }(\mathrm{mg} / \ell) \\
\text { Meses }\end{array}$}} & \multirow{2}{*}{\multicolumn{2}{|c|}{$\begin{array}{c}\mathrm{pH} \\
\text { Meses }\end{array}$}} & \multicolumn{2}{|c|}{ CONDUTIVIDADE $(\mu \mathrm{s} / \mathrm{cm})$} \\
\hline & & & & & & & \\
\hline & & Fevereiro & Julho & Fevereiro & Julho & Fevereiro & Julho \\
\hline 1 & $\begin{array}{l}\text { Superfície } \\
\text { Fundo }\end{array}$ & - & $\begin{array}{r}2.8 \\
-\end{array}$ & - & $\begin{array}{l}6.6 \\
6.6\end{array}$ & - & $\begin{array}{l}59.6 \\
58.7\end{array}$ \\
\hline 11 & $\begin{array}{l}\text { Superficie } \\
\text { Fundo }\end{array}$ & - & $\begin{array}{l}4.0 \\
2.9\end{array}$ & - & $\begin{array}{c}6.6 \\
-\end{array}$ & - & $\begin{array}{r}63.2 \\
-\end{array}$ \\
\hline
\end{tabular}


Os valores de $\mathrm{pH}$, também não mostraram nenhuma variação entre as duas estações, observando-se uniformidade da superfície até o fundo, cujo valor foi de 6.6.

A condutividade desse lago é relativamente alta, com valor de 60.5 us $_{25} / \mathrm{cm}$, não havendo diferenças marcantes entre as duas estaçōes consideradas e também entre as de superfície e do fundo.

Nutrientes inorgânicos - Fósforo total, nitrato e silicato "reativo".

$\mathrm{Na}$ tabela IV, são apresentados os valores encontrados, nas duas estações do lago Redondo.

TABELA IV - Nutrientes inorgânicos nas várias Estações dos lagos Redondo, Castanho, Jacaretinga, Cristalino e Tarumã-Mirim no mês de julho

LAGO REDONDO

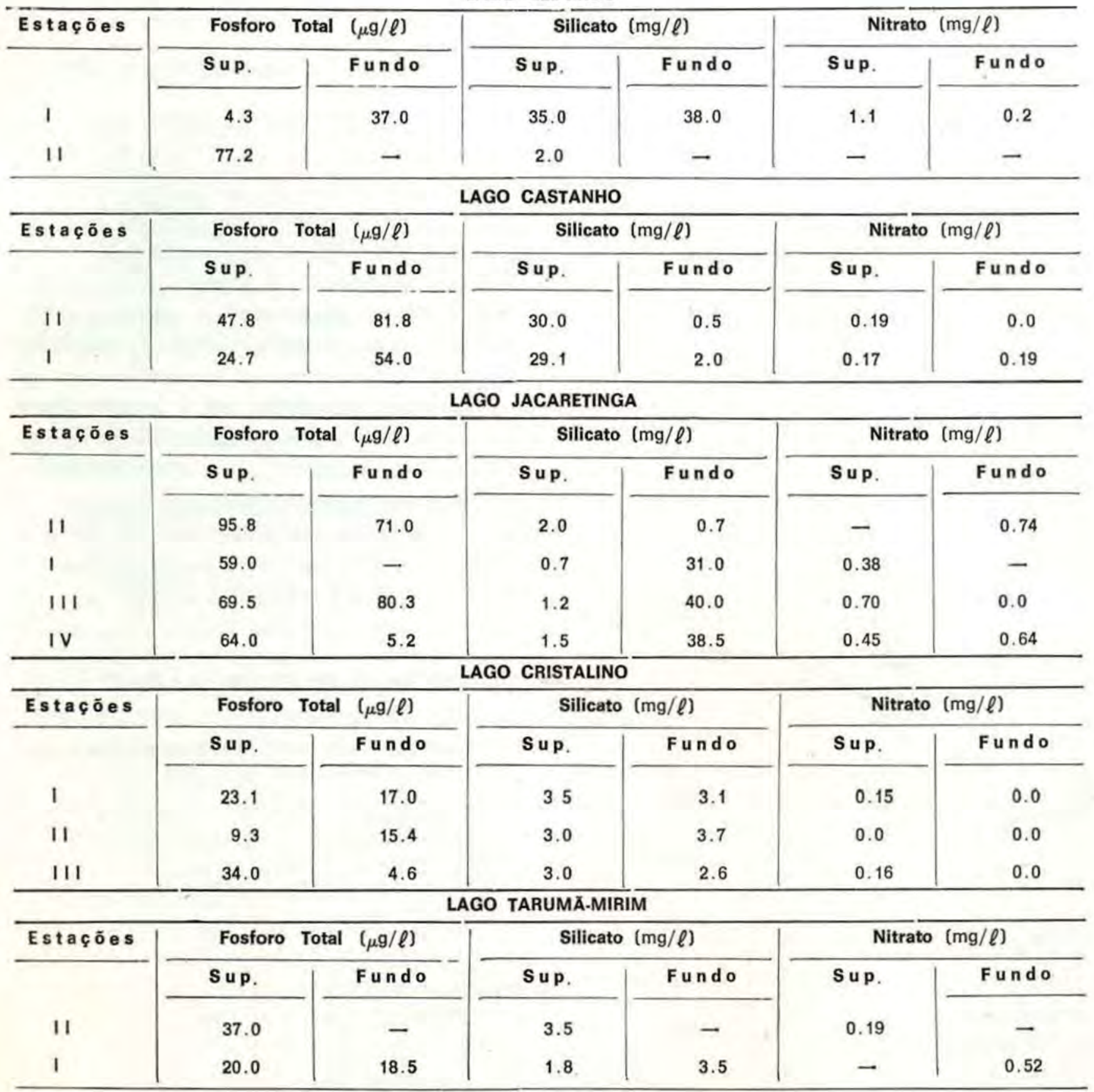


Os valores de fósforo total foram diferentes para as estaçōes I e II, oscilando entre 4.3 e $77.2 \mathrm{ug} / \mathrm{l}$. A contribuição de material alóctone na estação I é possivelmente muito grande. dada a sua localização nas proximidades da margem do lago que, provavelmente, acumula mais material que em outras regiões.

Os valores de silicato foram similares, nas duas profundidades da estação I $(350$ e $38.0 \mathrm{mg} / \mathrm{I}$ ). Na estação II, só foi obtido o valor da superfície.

O valor máximo de nitrato foi obtido na estação I. $\mathrm{Mg}^{++}$

lons: $\mathrm{Ca}^{++}, \mathrm{Mn}^{++}, \mathrm{Na}^{+}, \mathrm{K}^{+}, \mathrm{Zn}^{++} \mathrm{e}$

A composição iônica é mostrada na tabela V. Exceto os ions de $\mathrm{Mn}^{++}$e $\mathrm{Zn}^{++}$que não foram detectados, todos os outros ions

TABELA V - Valores de concentraçāo iônica em ppm no lago Redondo, em duas épocas do ano (fevereiro e julho de 1977)

\section{LAGO REDONDO}

Fevereiro de 1977

\begin{tabular}{|c|c|c|c|c|c|c|}
\hline $\begin{array}{l}\text { Profundi- } \\
\text { dade }(\mathrm{m})\end{array}$ & $\mathrm{Ca}++$ & $\mathrm{Mn}^{++}+$ & $\mathrm{Na}+$ & $\mathrm{K}+$ & $\mathrm{Zn++}$ & $\mathrm{Mg}++$ \\
\hline 0.0 & 2.41 & N.D. $(*)$ & 5.20 & 1.07 & N.D. & 0.81 \\
\hline \multirow[t]{2}{*}{20} & 3.70 & N.D. & 3.32 & 1.05 & N.D. & 1.21 \\
\hline & \multicolumn{6}{|c|}{ Julho de 1977} \\
\hline $\begin{array}{l}\text { Profundi- } \\
\text { dade (m) }\end{array}$ & $\mathrm{Ca}^{++}$ & $\mathrm{Mn}^{++}+$ & $\mathrm{Na}+$ & $\mathrm{K}+$ & $\mathrm{Zn}^{+}+$ & $\mathrm{Mg}^{++}$ \\
\hline 0.0 & 3,82 & N.D. & 2.44 & 1.02 & N.D. & 0.93 \\
\hline 4.0 & 4.32 & N.D. & 3.03 & 0.53 & N.D. & 1.11 \\
\hline
\end{tabular}

(*) - Não dectado.

estiveram presentes, sendo que $\mathrm{Na}^{+}$e $0 \mathrm{Ca}^{++}$ foram os íns de maiores concentraçōes. En. tretanto, a ordem de concentração desses íns diferiu, nas duas épocas analisadas: em fevereiro obteve-se, $\mathrm{Na}^{+}>\mathrm{Ca}^{++}>\mathrm{K}^{+}>\mathrm{Mg}^{++} \mathrm{e}$ em julho, $\mathrm{Ca}^{+}>\mathrm{N}^{+}>\mathrm{Mg}^{++}>\mathrm{K}^{+}$

\section{Lago Castanho}

Temperatura - A figura 5, mostra a dis tribuição vertical da temperatura da água nos meses de fevereiro e julho. Este lago apresenta uma distribuição vertical de temperatura, aproximadamente homogênea, tanto em feve-

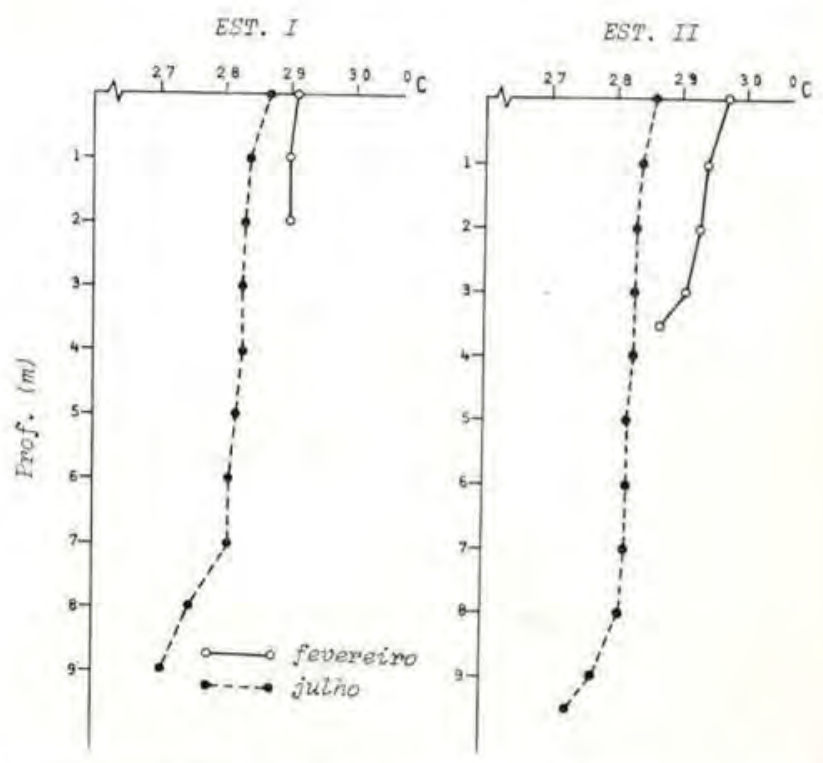

Fig. 5 - Perfil de temperatura $\left({ }^{\circ} \mathrm{C}\right)$ nas estaçōes I e II do lago Castanho, em duas épocas do ano.

reiro, quando o lago se apresenta relativamente raso (profundidade média $3.6 \mathrm{~m}$ ), como no mês de julho (época da cheia, quando o lago atinge profundidades médias maiores, de 10.0 $\mathrm{m})$. Houve, apenas, ligeira queda de temperatura a partir de $7.0 \mathrm{~m}$, na estação I e a partir de $8.0 \mathrm{~m}$, na estação II. Portanto, em termos de distribuição térmica, o lago se comporta, uniformemente, tanto no sentido horizontal como no vertical.

Oxigênio dissolvido, $\mathrm{pH}$ e condutividade Os dados relativos a oxigênio dissolvido, $\mathrm{pH}$ e condutividade das estações I e II são apresentadas, na tabela VI. As concentrações de oxigênio dissolvido, nas duas estações, apresentaram pequenas variantes.

No mês de fevereiro, as águas estavam mais oxigenadas que em julho, desde a superfície até o fundo, com valores médios de 5.2 $\mathrm{mg} / \mathrm{l}$ e $2.1 \mathrm{mg} / \mathrm{l}$ respectivamente. 
TABELA VI - Dados de oxigênio dissolvido $(\mathrm{mg} / \ell)$. pH e condutividade $(\mu \mathrm{s} / \mathrm{cm})$ nas estaçōes I e II do lago Castanho, obtidos nos meses de fevereiro e julho.

\begin{tabular}{|c|c|c|c|c|c|c|c|}
\hline \multirow{2}{*}{ Estaçōes } & \multirow{2}{*}{$\begin{array}{ll} & \text { Meses } \\
\text { Prof. } & \end{array}$} & \multicolumn{2}{|c|}{$\mathrm{O}_{2}$ DISSOLVIDO $(\mathrm{mg} / \ell)$} & \multicolumn{2}{|c|}{ pH } & \multicolumn{2}{|c|}{ CONDUTIVIDADE $(\mu \mathrm{s} / \mathrm{cm})$} \\
\hline & & Fevereiro & Julho & Fevereiro & Julho & Fevereiro & Julho \\
\hline \multirow[t]{2}{*}{1} & Superficie & 6.2 & 3.4 & 7.6 & 6.6 & 53.1 & 32.7 \\
\hline & Fundo & 5.7 & 1.4 & - & 6.6 & - & 43.6 \\
\hline \multirow[t]{2}{*}{ II } & Superfície & 5.0 & 2.1 & - & 6.6 & 51,4 & 37.3 \\
\hline & Fundo & 4.0 & 1.7 & 7.4 & 6.6 & - & 40.9 \\
\hline
\end{tabular}

$\mathrm{O} \mathrm{pH}$ da água variou de 6.6 a 7.6. No mês de julho, o pH manteve-se constante nas várias profundidades (superfície e fundo). Já em fevereiro, ocorreu ligeiro aumento do $\mathrm{pH}$, nas duas estações.

A condutância específica do lago, no mês de fevereiro foi mais alta que no mês de jutho com valores médios de $52.2 \mathrm{us}_{25} / \mathrm{cm}$. A condutividade medida nas camadas do fundo no mês de julho, foi ligeiramente maior que a da superfície.

Nutrientes inorgânicos - Fosfatos, nitratos e silicato "reativo".

As concentrações destes nutrientes são mostrados na tabela IV.

Fósforo total - As concentrações máximas ocorreram na estação I, com grandes diferenças entre as águas da superfície e as do fundo, sendo que seus valores foram, respectivamente, de $47.8 \mathrm{ug} / \mathrm{l}$ e $81.8 \mathrm{ug} / \mathrm{l}$. As concentraçōes de fósforo, na estação II foram mais baixos que na estação I, mostrando uma distribuição diferente deste elemento, no lago, tanto no sentido vertical como no horizontal.

Nitrato - As concentraçōes de nitrato foram geralmente baixas, variando de 0.19 a $0.17 \mathrm{mg} / \mathrm{l}$.

Silicato "reativo" - As concentrações de silicato reativo foram altas, na superfície, nas estaçōes I e II (30.0 e $29.1 \mathrm{mg} / \mathrm{l})$. Nas águas do fundo as concentrações foram baixas, em ambas as estações, com valores respectivos de 0.5 e $2.0 \mathrm{mg} / \mathrm{l}$.

$$
\begin{aligned}
& \text { lons }-\mathrm{Ca}^{++}, \mathrm{Mn}^{++}, \mathrm{Na}^{+} \mathrm{K}^{+}, \mathrm{Zn}^{++} \mathrm{e} \\
& \mathrm{Mg}^{++} .
\end{aligned}
$$

Como mostra a tabela 7 , os íons de $\mathrm{Ca}^{++}$ e $\mathrm{Na}^{+}$ocorreram em maiores concentraçōes tanto no mês de fevereiro como em julho. Porém, a ordem de concentração de íons analisados diferiu, nas duas épocas: em fevereiro obteve-se: $\mathrm{Na}^{+}>\mathrm{Ca}^{++}>\mathrm{K}+>\mathrm{Mg}^{++}>$e em julho $\mathrm{Ca}^{++}>\mathrm{Na}^{+}>\mathrm{K}^{+}>\mathrm{Mg}^{++}$.

TABELA VII - Valores de concentração iônica em ppm no lago Castanho em duas épocas do ano (fevereiro e julho de 1977)

\section{LAGO CASTANHO}

\begin{tabular}{|c|c|c|c|c|c|c|}
\hline $\begin{array}{l}\text { Profundi- } \\
\text { dade (m) }\end{array}$ & $\mathrm{Ca}+ \pm$ & $\mathrm{Mn}^{++}$ & $\mathrm{Na}+$ & $\mathbf{K}+$ & $\mathrm{Zn++}$ & $\mathrm{Mg}++$ \\
\hline \multirow[t]{2}{*}{0.0} & 3.94 & N.D. $\left({ }^{*}\right)$ & 6.93 & 1.47 & N.D. & 129 \\
\hline & \multicolumn{6}{|c|}{ Julho de 1977} \\
\hline $\begin{array}{l}\text { Profundi- } \\
\text { dade (m) }\end{array}$ & $\mathrm{Ca}++$ & $\mathrm{Mn}++$ & $\mathrm{Na}+$ & $\mathbf{k}+$ & $\mathrm{Zn++}$ & $\mathbf{M g}++$ \\
\hline 0.0 & 2.70 & N.D & 1.92 & 0.66 & 0.10 & 0.71 \\
\hline 2.0 & 2,30 & N.D. & $\rightarrow$ & 1.14 & N.D. & 0.89 \\
\hline 4.0 & 2.83 & N.D. & 3.57 & 0.93 & N.D. & 0.87 \\
\hline 6.0 & 3.00 & N.D. & 1.88 & 0.71 & N.D. & 0.77 \\
\hline 8.0 & 3.14 & N.D. & 4.40 & 1.11 & N.D, & 0.94 \\
\hline
\end{tabular}

Fevereiro de 1977 


\section{Lago Jacaretinga}

Temperatura - Na figura 6, está represen tado o gradiente térmico, observado nas diversas estações do lago Jacaretinga, nos meses de fevereiro e julho.

Em fevereiro, as temperaturas sofreram grandes flutuações, nas quatro estações analisadas (estação I, II, III e IV) nas profundidades entre a superfície e o fundo.
$\mathrm{Na}$ estação I, onde a profundidade local foi de $0,70 \mathrm{~cm}$, a temperatura teve um declínio de $0,3^{\circ} \mathrm{C}$, no fundo.

$\mathrm{Na}$ estação II, o declínio foi de $2,7^{\circ} \mathrm{C}$ entre as camadas da superfície e do fundo $(0,90 \mathrm{~cm})$. Já na estação III, onde a profundidade máxima foi de $2,0 \mathrm{~m}$, a queda de temperatura, entre a superfície e o fundo, foi de $2,4^{\circ} \mathrm{C}$. Esta mesma amplitude ocorreu na estação IV, entre a superfície $(0,0 \mathrm{~m})$ e o fundo $(1,70 \mathrm{~m})$.
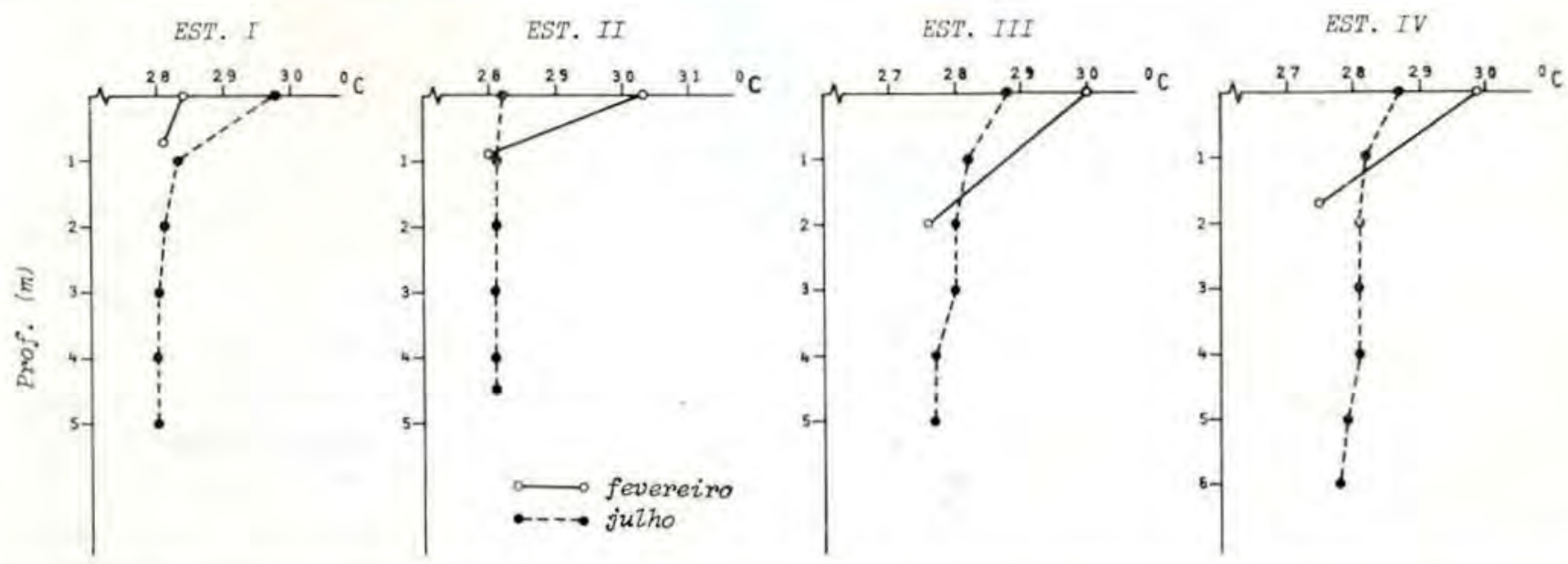

Fig. 6-Perfil de temperatura $\left({ }^{\circ} \mathrm{C}\right)$ nas estaçôes I, II, III e IV do lago Jacaretinga, em duas épocas dc ano.

No mês de julho, quando o lago atingiu maior profundidade (média de $5,0 \mathrm{~m}$ ) a temperatura mostrou uma distribuição mais uniforme em toda a coluna d'água, excetuando-se a estação I, onde se obteve uma diferença de $1,4^{\circ} \mathrm{C}$ entre a camada de $0,0 \mathrm{~m}$ e $1,0 \mathrm{~m}$.

Oxigênio dissolvido, $\mathrm{pH}$ e condutividade - Como mostra a tabela VIII, os valores de oxigênio dissolvido, $\mathrm{pH}$ e condutividade, apresentaram variaçōes nos dois períodos de estudo.

No mês de fevereiro, as concentrações de oxigênio dissolvido foram mais altas que no mês de julho, havendo diferenças entre as quatro estações estudadas. O menor valor encontrado foi, na estação I $(6,4 \mathrm{mg} / \mathrm{l})$ e o maior, na estação III $(8,9 \mathrm{mg} / \mathrm{I})$.

No mês de julho, verificou-se desoxigenação das águas, principalmente das camadas do fundo das estações I $(2,8 \mathrm{mg} / \mathrm{l})$ e II $(2,1 \mathrm{mg} / \mathrm{l})$.
$\mathrm{O} \mathrm{pH}$, neste lago, apresentava-se ligeiramente mais alcalino, no mês de fevereiro, que no de julho, mantendo-se constante em todas as estações. Os valores médios foram respectivamente de 7,6 e 6,5.

A condutância especifica foi ligeiramente mais alta no mês de fevereiro, quando apresentou valor médio de $51.4 \mathrm{us}_{25} / \mathrm{cm}$ e, no mês de julho, se obtiveram $45,1 \mathrm{us}_{25} / \mathrm{cm}$.

Nutrientes Inorgânicos - Os valores do fósforo total, nitrato e silicato "reativo", para o lago Jacaretinga, estão apresentados, na ta bela IV. Nas quatro estações estudadas houve variação de 59.0 a $95.8 \mathrm{ug} / \mathrm{l}$ de fósforo total. na superfície. Nas camadas do fundo, a flutuação foi maior, entre as estações, obtendo-se um mínimo de $5,2 \mathrm{ug} / \mathrm{I}$ na estação IV, e um máximo de 80,3 na estação III.

Silicato - As concentrações de silicato "reativo" nas águas do fundo do lago, nas qua 
TABELA VIII - Dados de oxigênio dissolvido $(\mathrm{mg} / \ell), \mathrm{pH}$ e condutividade $(\mu \mathrm{s} / \mathrm{cm})$ nas estações I, II, III e IV do lago Jacaretinga, obtidos nos meses de fevereiro e julho

\begin{tabular}{|c|c|c|c|c|c|c|c|}
\hline \multirow{2}{*}{ Estaçōes } & \multirow[t]{2}{*}{ Meses } & \multicolumn{2}{|c|}{$\mathrm{O}_{2}$ DISSOLVIDO $(\mathrm{mg} / \ell)$} & \multicolumn{2}{|c|}{$\mathrm{pH}$} & \multicolumn{2}{|c|}{ CONDUTIVIDADE $(\mu \mathrm{s} / \mathrm{cm})$} \\
\hline & & Fevereiro & Julho & Fevereiro & Julho & Fevereiro & Julho \\
\hline \multirow[t]{2}{*}{1} & Superfície & 6.4 & 4.8 & 7.6 & 6.5 & 48.8 & 47.2 \\
\hline & Fundo & - & 2.8 & - & 6.5 & 50.9 & 57.1 \\
\hline \multirow[t]{2}{*}{11} & Superfície & 7.8 & 2.8 & 7.6 & 6.6 & 54.4 & 45.8 \\
\hline & Fundo & - & 2.1 & - & 6.6 & 54.4 & - \\
\hline \multirow[t]{2}{*}{111} & Superficie & 8.9 & 3.5 & 7.6 & 6.4 & 50.4 & 25.2 \\
\hline & Fundo & - & 3.5 & - & 6.6 & 50.4 & 60.4 \\
\hline \multirow[t]{2}{*}{ IV } & Superfície & 8.5 & 4.9 & 7.9 & 6.5 & 51.0 & 42.8 \\
\hline & Fundo & - & 3.6 & - & 6.5 & - & 37.3 \\
\hline
\end{tabular}

tro estações, foram bem maiores que as da superfície, com exceção da estação I, cujo valor de silicato no fundo foi de $0.7 \mathrm{mg} / \mathrm{l}$; as outras estaçōes apresentaram uma média de $3.5 \mathrm{mg} / /$ contra $1.5 \mathrm{mg} / \mathrm{I}$ da superfície.

Nitrato - As concentrações de nitrato. apresentaram os seguintes valores médios na superfície e no fundo $(0,5$ e $0,4 \mathrm{mg} / \mathrm{l})$. $\mathrm{Mg}^{++}$

$$
\text { lons }-\mathrm{Ca}^{++}, \mathrm{Mn}^{++}, \mathrm{Na}^{+}, \mathrm{K}^{+}, \mathrm{Zn}^{++} \mathrm{e}
$$

A concentração iônica, obtida em fevereiro e julho, no lago Jacaretinga, é mostrada na tabela IX. Os ions de $\mathrm{Ca}^{++}$e $\mathrm{Na}^{+}$foram os mais abundantes nos dois meses de estudo. As maiores concentrações em fevereiro estavam, na seguinte ordem: $\mathrm{Na}^{++}>\mathrm{Ca}^{++}>$ $\mathrm{K}^{+}>\mathrm{Mg}^{++}$e em julho, $\mathrm{Na}^{+}>\mathrm{Ca}^{++}>\mathrm{K}^{+}>$ $\mathrm{Mg}^{++}>\mathrm{Zn}^{++}$. O $\mathrm{Zn}^{++}$foi detectado em pequena concentração, no mês de julho (0.2ppm).

\section{Lago Cristalino}

Temperatura - A figura 7, mostra a distribuição vertical da temperatura da água nas três estaçōes do lago Cristalino, nos meses de fevereiro e julho. Em fevereiro, ela se apresentou uniforme, da superfície ao fundo.

No mês de julho, observou-se queda gradual, a partir das profundidades de $2.0 \mathrm{~m}$ e $3,0 \mathrm{~m}$, nas estações I e II e a partir de $3,0 \mathrm{~m}$, na estação III.

Oxigênio dissolvido, $\mathrm{pH}$ e condutividade - São apresentados na tabela $X$, os dados de oxigênio dissolvido, $\mathrm{pH}$ e condutividade, obti-
TABELA IX - Valores de concentração iônica em ppm no lago Jacaretinga, em duas épocas do ano (f́evereiro s julho de 1977)

\section{LAGO JACARETINGA}

Fevereiro de 1977

\begin{tabular}{|c|c|c|c|c|c|c|}
\hline $\begin{array}{l}\text { Profundi- } \\
\text { dade }(m)\end{array}$ & $\mathrm{Ca}^{++}$ & $\mathrm{Mn}_{-+}^{+}$ & $\mathrm{Na}+$ & $\mathbf{K} \pm$ & $\mathrm{Zn++}$ & $\mathrm{Mg}++$ \\
\hline 0.0 & 2.80 & N.D. $\left(^{*}\right)$ & 8.06 & 2.08 & N.D. & 1.15 \\
\hline 1.0 & 3.94 & N,D. & 3.57 & 1.61 & N.D. & 1.15 \\
\hline \multirow[t]{2}{*}{2.0} & 3.09 & N.D. & 3.57 & 1.61 & N.D. & 1.03 \\
\hline & \multicolumn{6}{|c|}{ Julho de 1977} \\
\hline $\begin{array}{l}\text { Profundi- } \\
\text { dade }(m)\end{array}$ & $\mathrm{Ca}+ \pm$ & $\mathrm{Mn}++$ & $\mathrm{Na}+$ & $\mathbf{K} \pm$ & $\mathbf{Z n + +}$ & $\mathrm{Mg}^{++}+$ \\
\hline 0.0 & 3.82 & N.D. & 5.28 & 1. 10 & N.D. & 1.06 \\
\hline 20 & 2.98 & N.D. & 4.86 & 0.91 & N D. & 0.93 \\
\hline 4.0 & 4.00 & N.D. & 3.63 & 1.03 & 0.20 & 1.16 \\
\hline
\end{tabular}

dos nas três estações do lago Cristalino, durante o período de estudo.

No mês de fevereiro, as estações I, II e III se apresentaram oxigenadas, com valor médio de $6,7 \mathrm{mg} / \mathrm{l}$, tanto na superfície como no fundo, entretanto, houve nítida desoxigenaçāo nas camadas mais profundas das estações I. II e III $(1,0 \mathrm{mg} / \mathrm{l})$ no mês de julho. 

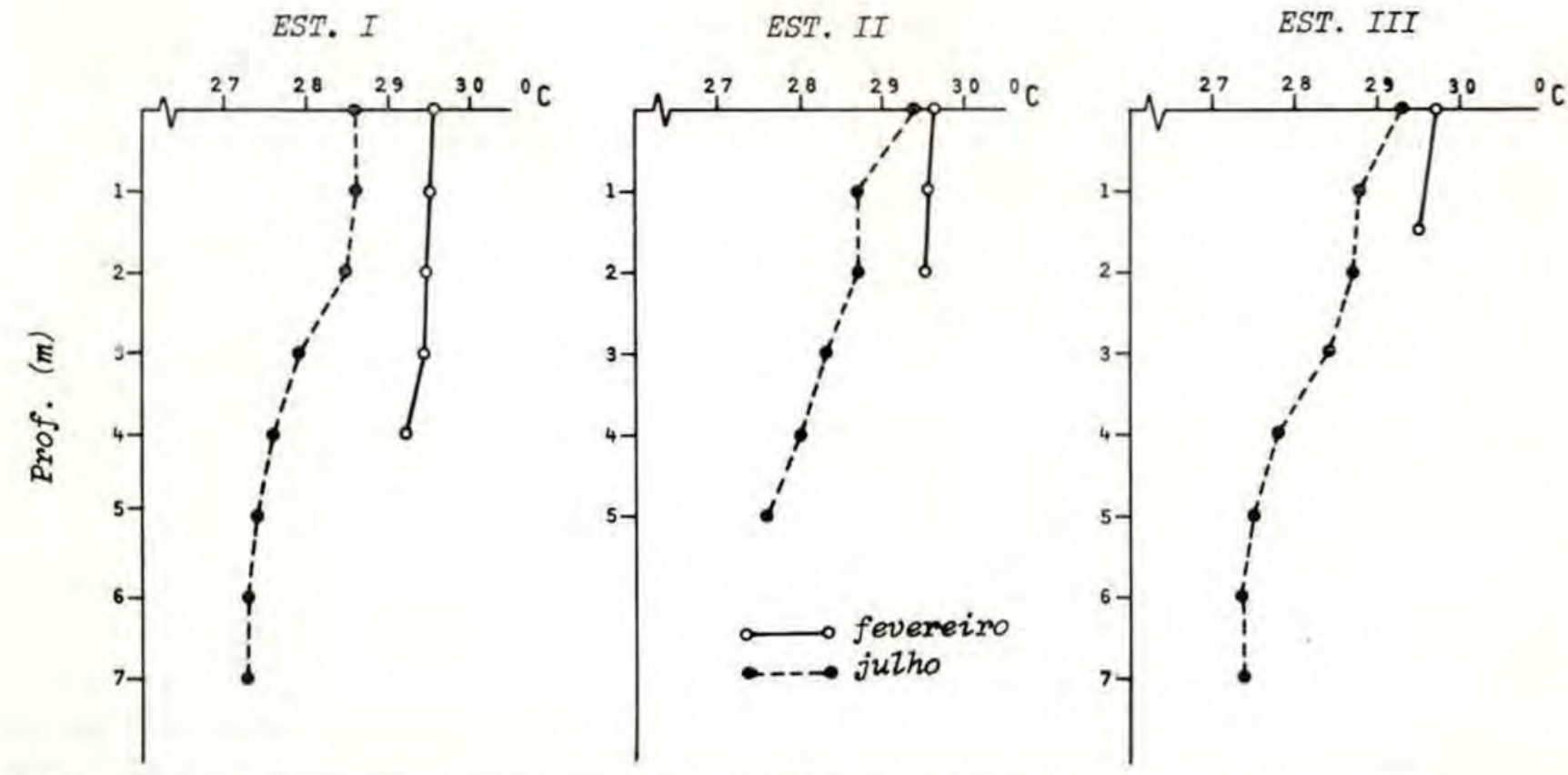

Fig. 7 - Perfil de temperatura $\left({ }^{\circ} \mathrm{C}\right)$ nas estações I, II e III do lago Cristalino, em duas épocas do ano.

TABELA X - Dados de oxigênio dissolvido $(\mathrm{mg} / \ell)$, pH e condutividade $(\mu \mathrm{s} / \mathrm{cm})$ nas estaçōes I, II e III do lago Cristalino, obtidos nos meses de fevereiro e julho.

\begin{tabular}{|c|c|c|c|c|c|c|c|}
\hline \multirow{2}{*}{ Estaçōes } & \multirow{2}{*}{$\begin{array}{ll} & \text { Meses } \\
\text { Prof. } & \end{array}$} & \multicolumn{2}{|c|}{$\mathrm{O}_{2}$ DISSOLVIDO $(\mathrm{mg} / \ell)$} & \multicolumn{2}{|c|}{$\mathrm{pH}$} & \multicolumn{2}{|c|}{ CONDUTIVIDADE $(\mu \mathrm{s} / \mathrm{cm})$} \\
\hline & & Fevereiro & Julho & Fevereiro & Julho & Fevereiro & Julho \\
\hline \multirow[t]{2}{*}{1} & Superfície & 6.7 & 6.0 & 5.2 & 5.4 & 3.4 & 7.3 \\
\hline & Fundo & - & 1.0 & 5.3 & 5.3 & 4.0 & 10.1 \\
\hline \multirow[t]{2}{*}{11} & Superfície & 7.2 & 6.0 & 5.5 & 5.4 & 3.8 & 8.4 \\
\hline & Fundo & 7.0 & 1.0 & 5.5 & 5.4 & 3.4 & 8.9 \\
\hline \multirow[t]{2}{*}{111} & Superfície & 7.0 & 7.0 & 5.1 & 5.4 & 3.8 & 8.5 \\
\hline & Fundo & 6.0 & 1.0 & 5.2 & 5.4 & - & 8.9 \\
\hline
\end{tabular}

Quanto ao $\mathrm{pH}$, os valores encontrados foram uniformes, em todas as estaçōes, tanto em fevereiro como em julho.

Os dados de condutividade se apresentaram mais baixos no mês de fevereiro, variando de 3,4 a 4,0 us $_{25} / \mathrm{cm}$; no mês de julho, houve aumento em todas as estações, com o valor médio de $8,6 \mathrm{us}_{25} / \mathrm{cm}$.

Nutrientes inorgânicos - Fosfatos, nitratos e silicato "reativo".
Como mostra a tabela IV, a concentração de fósforo total no lago teve distribuição irregular entre a superfície e o fundo, quando oscilou de 4,6 a $34,0 \mathrm{mg} / \mathrm{l}$.

Nitrato - Baixas concentraçōes de nitrato foram observadas, nas camadas superficiais das estaçōes I e II, não se registrando nas camadas do fundo.

$$
\text { lons }-\mathrm{Ca}^{++}, \mathrm{Mn}^{++}, \mathrm{Na}^{+}, \mathrm{K}^{+}, \mathrm{Zn}^{++} \mathrm{e}
$$
$\mathrm{Mg}^{++}$. 
Exceto os íons de $\mathrm{Mn}^{++}$e $\mathrm{Zn}^{++}$, que năo foram detectáveis, os outros ions ocorreram em baixas concentrações, nos meses de fevereiro e julho, como é visto na tabela XI. No mês de fevereiro, as concentrações dos íons tiveram a seguinte ordem:

$\mathrm{Na}^{+}>\mathrm{Ca}^{++}>\mathrm{K}^{+}>\mathrm{Mg}^{++}$e no mês de julho $\mathrm{Na}^{+}>\mathrm{Ca}^{++}>\mathrm{K}^{+}>\mathrm{Mg}^{++}$.

TABELA XI - Valores de concentraçăo iônica em ppm no lago Cristalino em duas épocas do ano (fevereiro e julho de 1977)

\section{LAGO CRISTALINO}

\begin{tabular}{|c|c|c|c|c|c|c|}
\hline \multirow[b]{2}{*}{$\begin{array}{l}\text { Profundi- } \\
\text { dade }(\mathrm{m})\end{array}$} & \multirow[b]{2}{*}{$\mathrm{Ca}^{++}+$} & \multirow[b]{2}{*}{$\mathrm{Mn}^{++}$} & \multicolumn{4}{|c|}{ Fevereiro de 1977} \\
\hline & & & $\mathrm{Na}+$ & $\mathrm{K}+$ & $\mathrm{Zn}++$ & $\mathrm{Mg}++$ \\
\hline 0.0 & 0.38 & N.D. $\left({ }^{*}\right)$ & N.D. & 1.36 & 1.11 & 0.09 \\
\hline 1.0 & 0.26 & N.D. & N,D. & 0.38 & 0.05 & 0.05 \\
\hline 2.0 & 0.36 & N.D. & N.D. & 0.73 & 0.10 & 0.08 \\
\hline \multirow[t]{2}{*}{3.0} & 0.20 & N.D & N.D. & 0.14 & 0.02 & 0.006 \\
\hline & \multicolumn{6}{|c|}{ Julho de 1977} \\
\hline $\begin{array}{l}\text { Profundi- } \\
\text { dade }(m)\end{array}$ & $\mathrm{Ca}^{++}$ & $\mathrm{Mn}++$ & $\mathrm{Na}+$ & $\mathbf{K +}$ & $\mathrm{Zn}++$ & $\mathrm{Mg}^{++}+$ \\
\hline 0.0 & 0.73 & N.D. & N.D. & 1.25 & 0.28 & 0.19 \\
\hline 4.0 & 0.60 & N.D. & N.D. & 1.27 & 0.28 & 0.17 \\
\hline 6.0 & 0.52 & N.D. & N.D. & 0.87 & 0.28 & 0.14 \\
\hline
\end{tabular}

(*) - Nõo detectado.

\section{Lago Tarumã-mirim}

Temperatura - A figura 8 mostra o perfil vertical da temperatura do lago Tarumã-mirim no mês de fevereiro e julho.

Em fevereiro, a estação I apresentou temperatura uniforme em toda a coluna d'água, porém, na estação II, houve ligeira irregularidade na sua distribuição.

No mês de julho, houve grande queda da temperatura, da superfície ao fundo, em ambas as estações.

Oxigênio dissolvido, $\mathrm{pH}$ e condutividade - Na tabela XII, são apresentados os valores
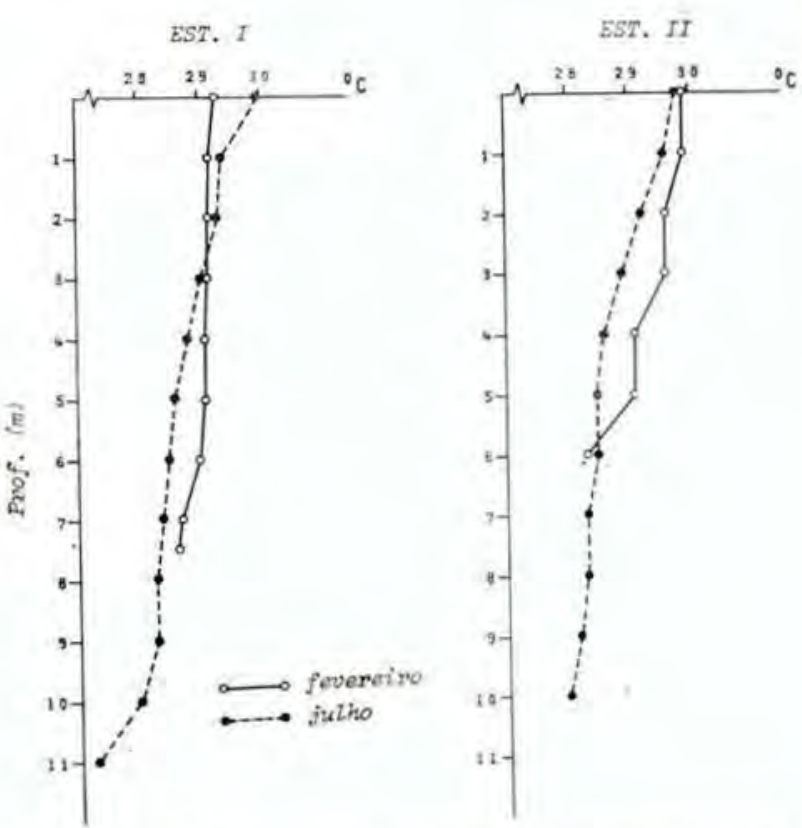

Fig. 8 - Perfil de temperatura $\left({ }^{\circ} \mathrm{C}\right)$ nas estaçôes I a II do lago Tarumã-Mirim, em duas épocas do ano.

de oxigênio dissolvido, $\mathrm{pH}$ e condutividade, obtidos nas estações I e II do lago Tarumä-mirim. em duas épocas do ano. Neste lago, o teor de oxigênio dissolvido, nas duas estações, foi maior em julho que em fevereiro, e as camadas do fundo apresentaram valores bem baixos $(1,0$ a $2,2 \mathrm{mg} / \mathrm{l})$.

$\mathrm{O} \mathrm{pH}$ foi constante $(5,0)$ nas duas estações, porém um pouco mais ácido que nos outros lagos.

Quanto à condutividade, os valores foram ligeiramente mais baixos, no mês de julho, do que em fevereiro (valores de 8,8 e $7,2 \mathrm{us}_{25} / \mathrm{cm}$ ), respectivamente.

Nutrientes inorgânicos - Fosfatos, nitrato e silicato "reativo".

$\mathrm{Na}$ tabela 4, são apresentadas as concentrações de fósforo total, nitrato e silicato "rea. tivo".

Fósforo total - Os valores obtidos nas estações I e II, na superficie, foram $20,0 \mathrm{ug} / \mathrm{I}$ e $37,0 \mathrm{ug} / \mathrm{I}$, respectivamente.

Silicato reativo - Apresentou uma concentração entre 1,8 e $3,5 \mathrm{mg} / \mathrm{I}$.

Nitrato - As concentrações de nitrato fo ram baixas, nas estações I e II $(0.19$ e 0.52 $\mathrm{mg} / \mathrm{l}$ ). 
TABELA XII - Dados de oxigênio dissolvido $(\mathrm{mg} / \ell)$, pH e condutividade $(\mu \mathrm{s} / \mathrm{cm})$ nas estaçöes I e II do lago Taru. mã.mirim, obtidos nos meses de fevereiro e julho.

\begin{tabular}{|c|c|c|c|c|c|c|c|}
\hline \multirow{2}{*}{ Estaçőes } & \multirow[t]{2}{*}{ Meses } & \multicolumn{2}{|c|}{$\mathrm{O}_{2}$ DISSOLVIDO $(\mathrm{mg} / \ell)$} & \multicolumn{2}{|c|}{$\mathrm{pH}$} & \multicolumn{2}{|c|}{ CONDUTIVIDADE $(\mu \mathrm{s} / \mathrm{cm})$} \\
\hline & & Fevereiro & Julho & Fevereiro & Julho & Fevereiro & Julho \\
\hline \multirow[t]{2}{*}{1} & Superficie & 5.5 & 8.0 & 5.0 & 5.0 & 8.6 & 7.3 \\
\hline & Fundo & - & 2.2 & 5.0 & 5.0 & 9.0 & 7.0 \\
\hline \multirow[t]{2}{*}{11} & Superfície & 5.0 & 7.6 & 5.0 & 5.0 & - & 7.5 \\
\hline & Fundo & 1.0 & 1.0 & 4.6 & - & - & 7.0 \\
\hline
\end{tabular}

$$
\begin{aligned}
& \text { lons }-\mathrm{Ca}^{++}, \mathrm{Mn}^{++}, \mathrm{Na}^{+}, \mathrm{K}^{+}, \mathrm{Zn}^{++} \mathrm{e} \\
& \mathrm{Mg}^{++} \text {. }
\end{aligned}
$$

Os íons de $\mathrm{Mn}^{++}$e $\mathrm{Zn}^{++}$não foram detectados nas águas do lago Tarumã-mirim, durante o período de estudo. Na tabela 13, observa-se que os outros íons estiveram presentes, em pequenas concentrações, exceto os de $\mathrm{Na}^{+}$e $\mathrm{K}^{+}$, que se apresentaram nas camadas mais profundas do lago, com altas concentrações, notadamente, no mês de fevereiro. A or-

TABELA XIII - Valores de concentração iônica em ppm no lago Tarumã-mirim, em duas épocas do ano (fevereiro e julho de 1977)

\begin{tabular}{|c|c|c|c|c|c|c|}
\hline & & \multicolumn{5}{|c|}{ Fevereiro de 1977} \\
\hline $\begin{array}{l}\text { Proiundi- } \\
\text { dade }(m)\end{array}$ & $\mathrm{Ca}++$ & $\mathrm{Mn}++$ & $\mathrm{Na}+$ & $\mathrm{K}+$ & $\mathbf{Z n + +}$ & $\mathrm{Mg}++$ \\
\hline 0.0 & 0.26 & N.D. $\left({ }^{*}\right)$ & 0.61 & 0.39 & N.D. & 0.16 \\
\hline 6.0 & 0.74 & N.D. & 6.20 & 0.47 & N.D. & 0.17 \\
\hline \multirow[t]{2}{*}{8.0} & 1.10 & N.D. & 11.9 & 5.29 & N.D. & 0.60 \\
\hline & \multicolumn{6}{|c|}{ Julho de 1977} \\
\hline $\begin{array}{l}\text { Profundi- } \\
\text { dade }(\mathrm{m})\end{array}$ & $\mathrm{Ca}++$ & $\mathrm{Mn}++$ & $\mathrm{Na}+$ & K+ & $\mathrm{Zn}++$ & $\mathrm{Mg}++$ \\
\hline 0.0 & 0.52 & N.D. & 0.97 & 0.25 & N.D. & 0.14 \\
\hline 12.0 & 0.52 & N.D. & 0.97 & 0.18 & N.D. & 0.15 \\
\hline
\end{tabular}

\section{LAGO TARUMĀ-MIRIM}

(*) - Não detectodo. dem de concentração dos vários íons em fevereiro, foi: $\mathrm{Na}^{+}>\mathrm{K}^{++}>\mathrm{Ca}^{++}>\mathrm{Mg}^{++} \mathrm{e}$, em julho: $\mathrm{Na}^{+}>\mathrm{Ca}^{++}>\mathrm{K}^{+}>\mathrm{Mg}^{++}$.

\section{ANÁLISE DOS PARÂMETROS BIOLÓGICOS}

"Standing-stock" do zooplancton e sua composição, nos diferentes lagos - $\mathrm{O}$ "standing-stock" do zooplancton foi composto por Cladocera, Rotifera (com lórica) Calanoida (náuplio, copepóditos e adultos) e Cyclopoida (náuplio, copepóditos e adultos).

Como pode ser observado na Tabela XIV, o valor do "standing-stock" variou de lago para lago, assim como para as duas épocas analisadas.

De modo geral, o maior valor de "standingstock" foi obtido em fevereiro para todos os lagos, perfazendo um total de $4.957 .304 \mathrm{ind} / \mathrm{m}^{3}$ contra 1.711 .493 ind $/ \mathrm{m}^{3}$ obtidos em julho.

Os que apresentaram maior densidade de organismos, em termos de número, foram os lagos de "água preta", Tarumā-mirim e lago Cristalino, respectivamente, com, 1.502.111 ind $/ \mathrm{m}^{3}$ e $2.944 .892 \mathrm{ind} / \mathrm{m}^{3}$, enquanto que lagos de "água branca", apresentaram menor número de organismos, sendo em ordem decrescente: Jacaretinga, Castanho e Redondo, com 1.451 .407 ind $/ \mathrm{m}^{3}, \quad 557.981$ ind $/ \mathrm{m}^{3}$ e 272.406 ind $/ \mathrm{m}^{3}$, respectivamente.

A composição de espécies do zooplancton, nestes lagos, mostrou também grandes variações.

Em termos de grupos, o Copepoda foi o mais abundante, em quase todos os lagos, seguido de Rotifera e Cladocera. Dentre os Co- 
TABELA XIV - "Standing-stock" do Zooplancton (n.० de ind $/ \mathrm{m}^{3}$ ) em 5 lagos da Região Amazônica nos meses de fevereiro e julho

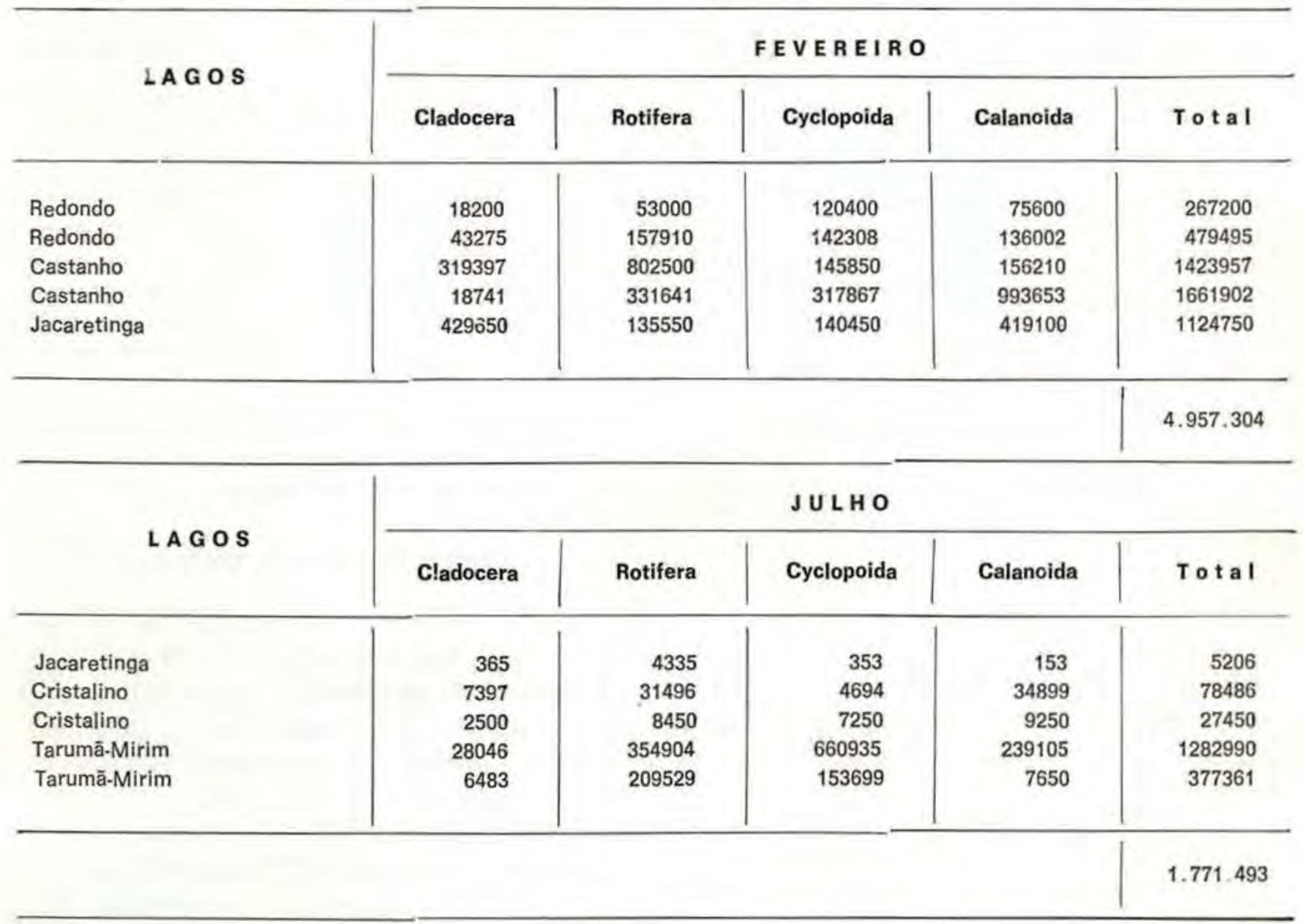

pepoda, os Calanoida foram sempre mais abundantes que os Cyclopoida, nos lagos de "água preta", no mês de fevereiro, porém, o inverso foi observado, em julho, nestes mesmos lagos.

Já nos lagos de "água branca", os Cyclopoida foram mais abundantes do que os Calanoida, no mês de fevereiro, acontecendo o inverso, em julho. Figura 9 .

Composição das espécies de Rotifera nos diferentes lagos - A figura 10 mostra o aspecto da composição relativa de várias espécies de rotíferos, nos 5 lagos estudados, nos meses de fevereiro e julho.

Em fevereiro, o lago Redondo foi caracterizado pela dominância de Keratella cochlearis constituindo $99,5 \%$ do total de rotíferos; o lago Jacaretinga pela predominância de Brachionus falcatus ( $92 \%$ do total de rotíferos), enquanto que o Castanho mostrou dominância de duas espécies: Keratella cochlearis e Brachionus dolabratus ( $26 \%$ e $24,5 \%$ ) respectivamente. Nos lagos de "água preta", tanto no Cristalino, como no Tarumā-mirim, não houve dominância marcante de uma única espécie, estando, sempre, tanto no Cristalino como no Tarumã-mirim, duas predominantes: Keratella cochlearis e Brachionus gessneri.

Sob a denominação de "outras espécies de rotíferos", foram incluídas aquelas que ocorreram, em pequenas porcentagens ou foram de rara ocorrência nas amostras, sendo as seguintes: Conochilus dossuarius, Tetramastix opoliensis brevispina, Testudinella mucronata haueriensis, Trichocerca similis grandis, Lecane elsa, Macrochaetus subquadratus, Mytilina ventralis, Keratella americana, Brachionus patulus macracanthus, Brachionus mirus voigti, Brachionus calyciflorus spinosus e Brachionus ah/stromi. 


\section{Redondo}
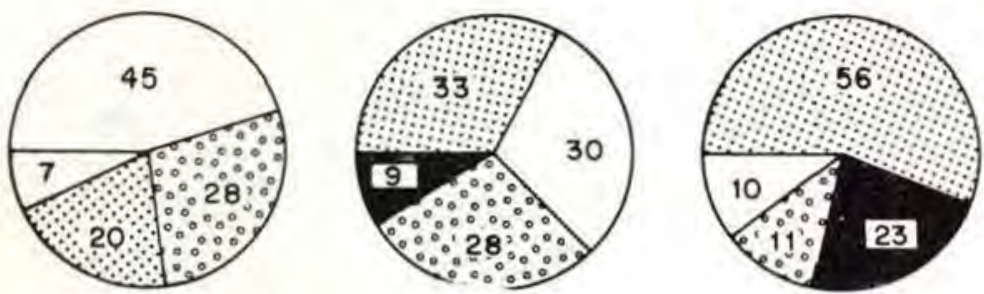

$J \cup L B O$
L. Cristalino
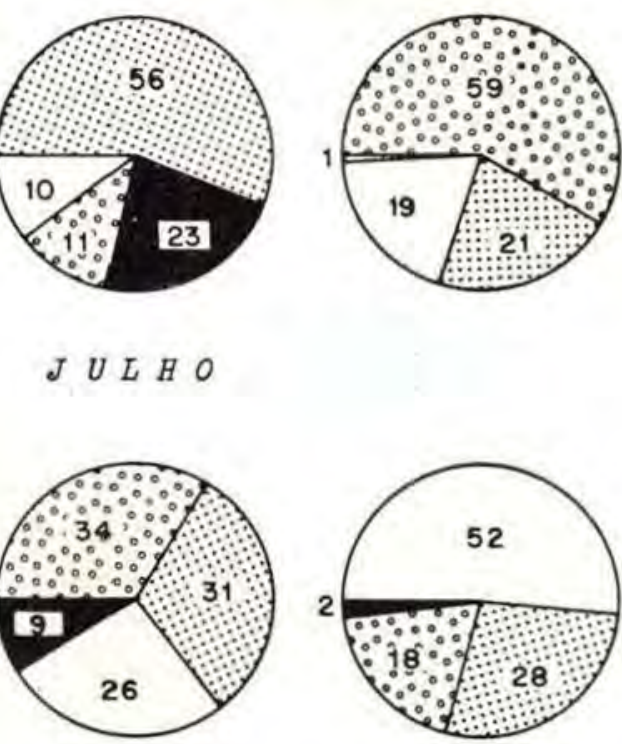

[i] Catanoida
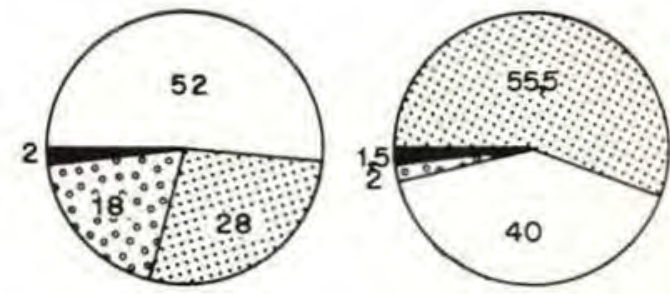

Cyelopoida
L. Tarnonä-Mirim
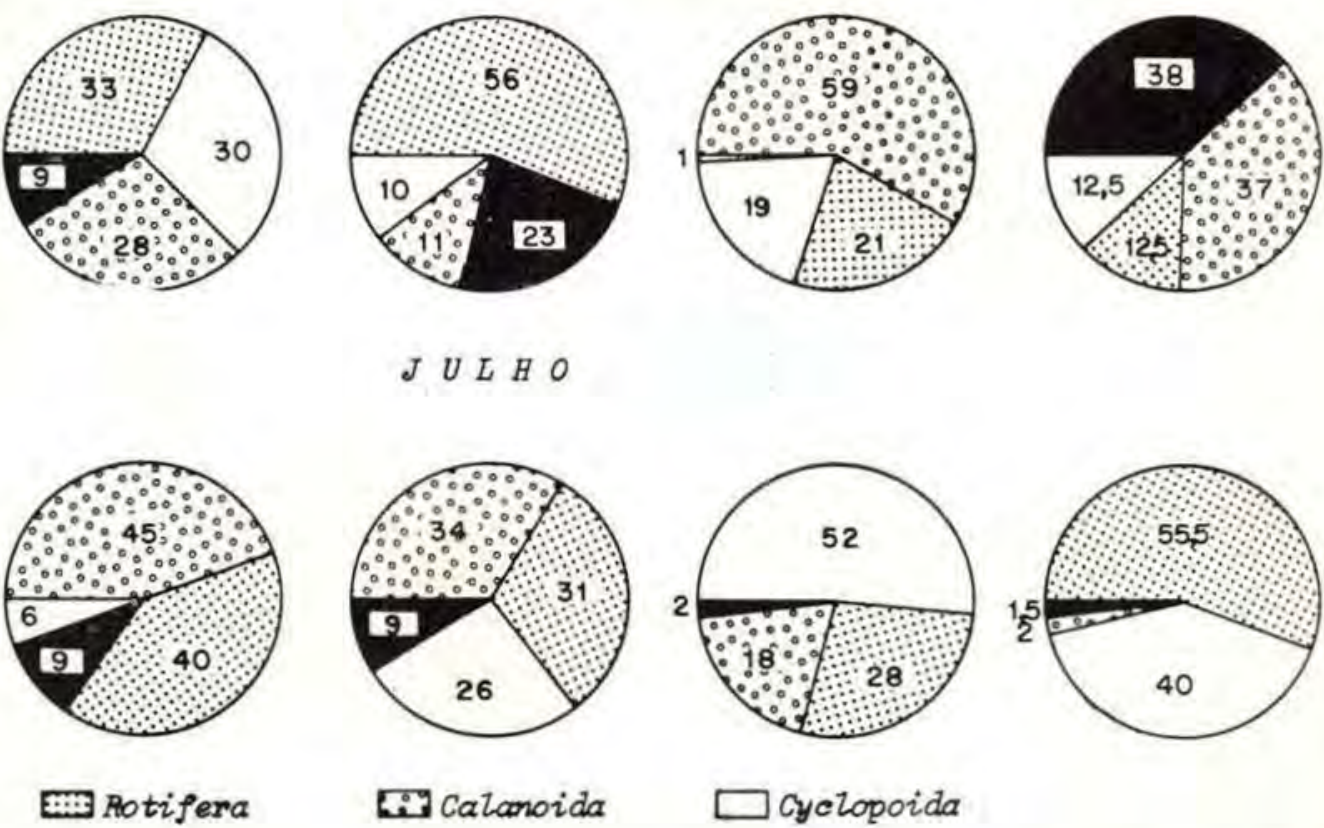

cladocera

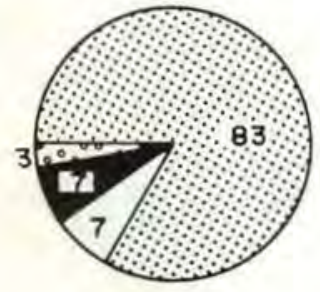

Fig. 9 - Composição relativa em \% do zooplancton em 5 lagos

No mês de julho, houve mudança total, na dominância das espécies, em todos os lagos, sendo que o Redondo foi caracterizado pelo maior número de duas espécies: Brachionus patulus e Hexarthra intermedia brasiliensis. No lago Jacaretinga, entretanto, não houve dominância específica, sendo que das 17 espécies de rotiferos, somente a Monostylla bulla registrou pequena dominância $(28,5 \%)$. No lago Castanho, houve aparecimento de outra espécie, Polyarthra vulgaris, passando a dominar a comunidade de rotíferos, da época da cheia, deste lago. Mesmo nos lagos de "água preta", outras espécies que não aquelas da época da vazante, passaram a destacar-se na comunidade. No lago Cristalino, Brachionus zahniseri reductus contribuiu com $49 \%$ enquanto, que no Tarumã-mirim, Polyarthra $\mathrm{sp}$. foi a mais abundante, contribuindo com $50 \%$ do total.

Composição das espécies de Cladocera nos diferentes lagos - A composição de Cladocera também foi variável de lago para lago, bem como de uma época para outra. A Figura
11 mostra a composição relativa das espécies de Cladocera, presentes nos diferentes lagos na época de vazante e na da cheia.

No mês de fevereiro, os lagos de "água branca" foram caracterizados por apresentarem uma espécie dominante, em cada um deles. No lago Redondo, foi Bosmina chilensis que contribuiu com $56 \%$ do total; no lago Jacaretinga foi a Moina reticulata com $50 \%$ do total; no lago Castanho a dominante foi representada por Ceriodaphnia cornuta, com $51 \%$ do total. Nos lagos de "água preta", houve dominância marcante de uma única espécie, Bosminopsis deitersi, contribuindo, respectivamente, com $84 \%$ e $89 \%$, nos lagos Cristalino e Tarumã-mirim.

No mês de julho, houve uma mudança na dominância das espécies nos lagos de "água branca". Neles, registrou-se o aparecimento da espécie Bosminopsis deitersi que passou a dominar a comunidade de cladoceros, neste periodo. Nos lagos Cristalino e Tarumā-mirim. continuou ela sendo a dominante contribuindo. respectivamente, com $72 \%$ e $92 \%$. 


\section{FEVEREIRO}

L. Redondo
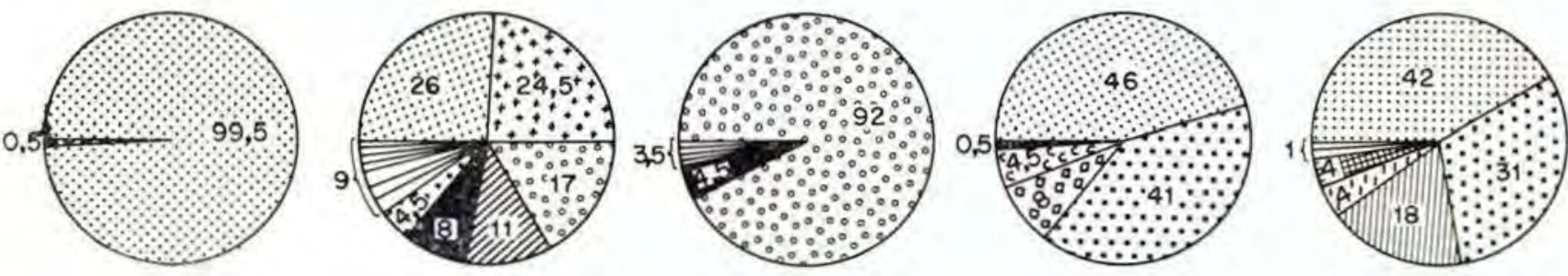

JULHO
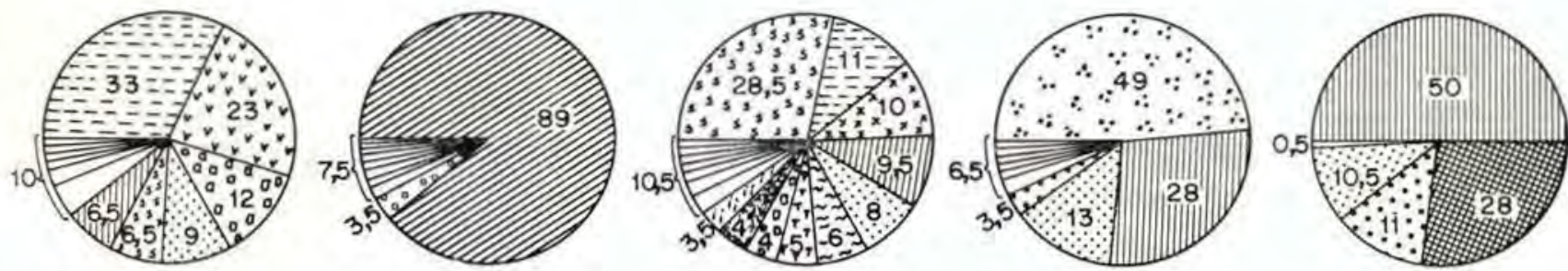

बध्ब Trichocerca similis

国星Brachionus patutus

W1200nostyla bulla

[- Brachionus z. reductus

kca Lecane sp.

Iini Trichocerca chattoni

wHexarthra int. bras.
Imichotria tetractis

Fu Lecane Ludwigi typica

ir Lecane leontina

(iii) Lecane mugosa

Platyas q. brevispinus

IIII Monos ty la sp.

$\square$ "Outras espécies de ro

Fig. 10 - Composiçăo relativa $\in m$ \% dos Rotifera em 5 la gos da região amazônica, nos meses de fevereiro e julho.

As espécies de Cladocera que contribuiram com menos de $0,5 \%$ do total foram agrupadas sob a denominação de "outras espécies". No lago Jacaretinga, foram: Daphnia gessneri e llyocryptus spinifer; no Tarumā-mirim foram: Ceriodaphnia cornuta, Diaphanosoma sarsi e Holopedium amazonicus; no Castanho: Bosmina chilensis, Daphnia gessneri, Macrotrix sp. e Chydorus sphaericus.

Composição das espécies de Copepoda nos diferentes lagos - A presença de três espécies de Calanoida: Notodiaptomus amazonicus, Notodiaptomus coniferoides e Aspinus aciculares podem ser observadas, nos lagos estudados, da região Amazônica. As formas adultas foram de ocorrência muito pequena. Já as formas de náuplius contribuiram com cerca de $98 \%$ do total, como pode ser visto na
Figura 12, não sendo possível distinguir as diferentes espécies de Calanoida neste estágio. Das três espécies Aspinus acicularis foi encontrado somente no lago Cristalino, no mês de fevereiro, sendo a única espécie de Calanoida (adulta), presente nos lagos de "água preta", em número reduzido (146 ind $\left./ \mathrm{m}^{3}\right)$.

Nos lagos de "água branca", somente no mês de fevereiro, observou-se a ocorrência das duas espécies de Notodiaptomus: coniferoides e amazonicus, sendo que, no lago Jacaretinga, houve a predominância de Notodiaptomus coniferoides $(24 \%)$ sobre Notodiaptomus amazonicus $(4,5 \%)$.

Quanto aos Cyclopoida, três espécies foram observadas: Mesocyclops leuckarti, Thermocyclops minutus e Oithona amazonica, sendo a Oithona amazonica o Cyclopoida mais 


\section{FEVEREIRO}

L. Redondo
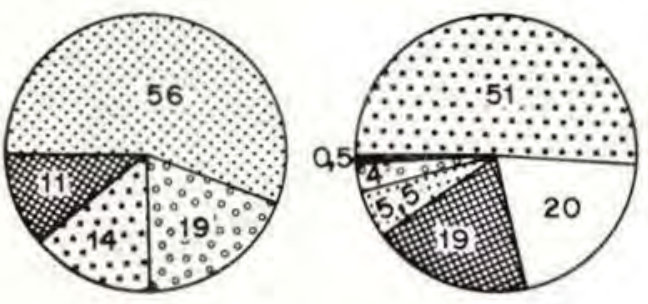

L. Castanho

L. Jacaretinga

L. Cristalino
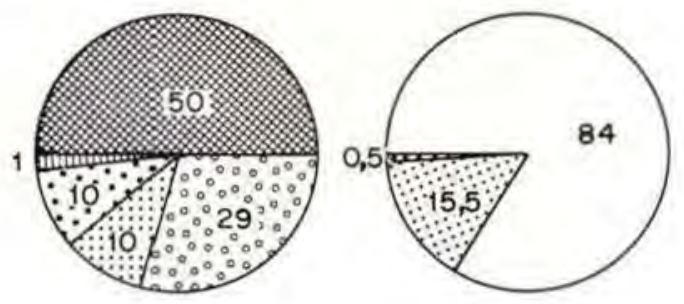

JULHO
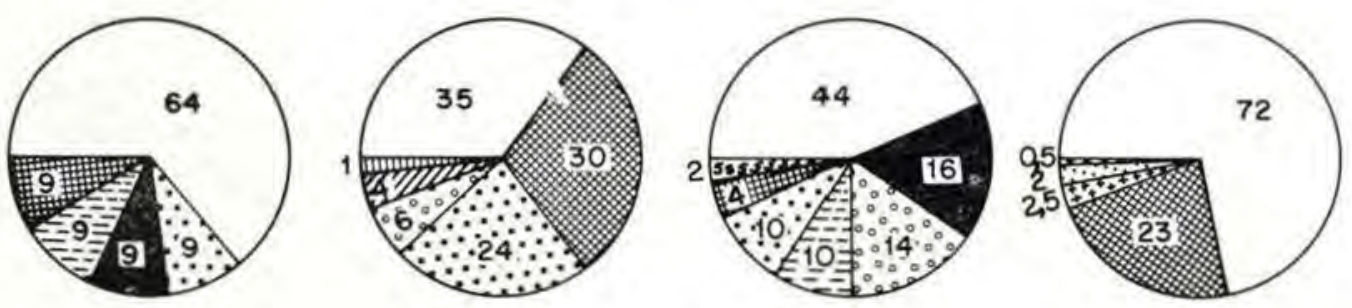

Chydoms sphaerious

IIIIII) "Outras espécies"

Macrotrix sp.

[3ss Latonopsis fascioulata
E- Bosmina chilensis

Bosminopsis deitersi

[.:: Bosminopsis negrensis

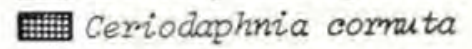

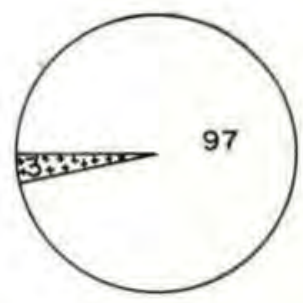

L. Tarwãä-Mimim

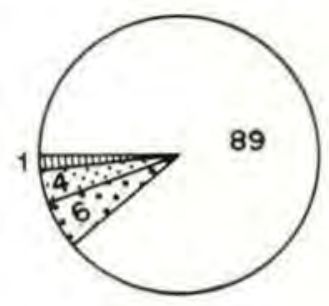

$\because$ Diaphanosoma sarsi

$\because$ Moina reticulata

[Mo Holopedivm comazonicum

IIII Ilyocriptus spinifer

Fig. 11 - Composição relativa em \% dos Cladocera em 5 lagos da região amazônica, nos meses de fevereiro e julho.

abundante, ocorrendo, em todos os lagos. Thermocyclops minutus foi observado nos lagos Castanho e Jacaretinga, nos dois períodos analisados e também no lago Tarumã-mirim, em julho. O Mesocyclops leuckarti ocorreu, somente, no lago Castanho no mês de julho, mas em quantidade infima $\left(33 \mathrm{ind} / \mathrm{m}^{3}\right)$.

A figura 13 mostra a composição relativa das três espécies de Cyclopoida na forma adulta; e as formas de náuplius e copepóditos, sem identificação, para as espécies.

Diversidade de espécies dos lagos e em diferentes localidades de cada lago.

Diversidade de espécies dos Cladocera A presença e a abundância de certas espécies de organismos, em determinados lagos e sua distribuição, dentro do mesmo lago, depende de inúmeros fatores físico-químicos e biológicos, os quais são responsáveis pelo sucesso ou insucesso de uma espécie, dentro de um ambiente. Os lagos, mesmo aqueles que se assemelham troficamente, apresentam características peculiares, ou por causa da estrutura do solo ou pela sua morfometria, fazendo com que dois lagos nunca sejam exatamente iguias. Desta maneira, a vida que depende destas características básicas também difere de um lago para outro.

Com o objetivo de estabeiecer uma proximidade entre os cinco lagos analisados, na Região Amazônica, quanto à presença e abundância das espécies de zooplancton, foram calculados índices de diversidade e equitatividade, principalmente dos Cladocera e dos Rotifera.

Em cada lago, a função "Shannon-Weaver" foi calculada para obter a medida de diversidade da fauna de rotíferos e de cladóceros.

A medida de equitatividade, proposta por Lloyd \& Ghelardi (1964), serve para comparar o número de espécies, realmente encontrado 


\section{FEVEREIRO}

L. Redondo
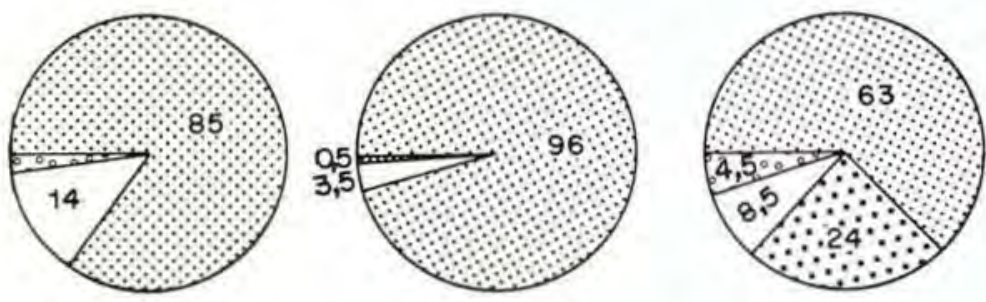

JULHO
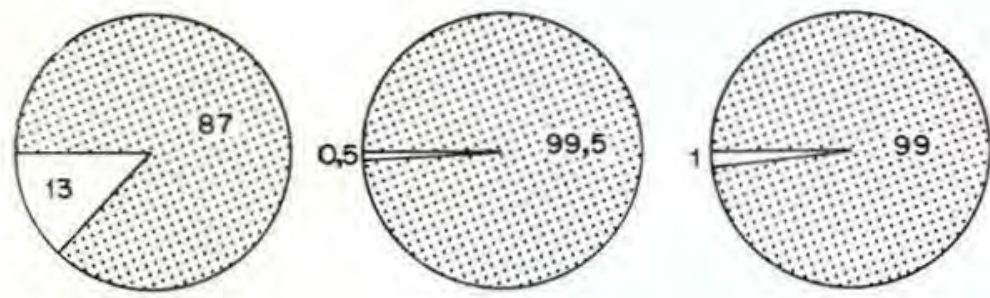

.7.7 Narplius

Aspinus aeiculanis

\section{$\square$ Copepodito}

… Notodioptomus coniferoides
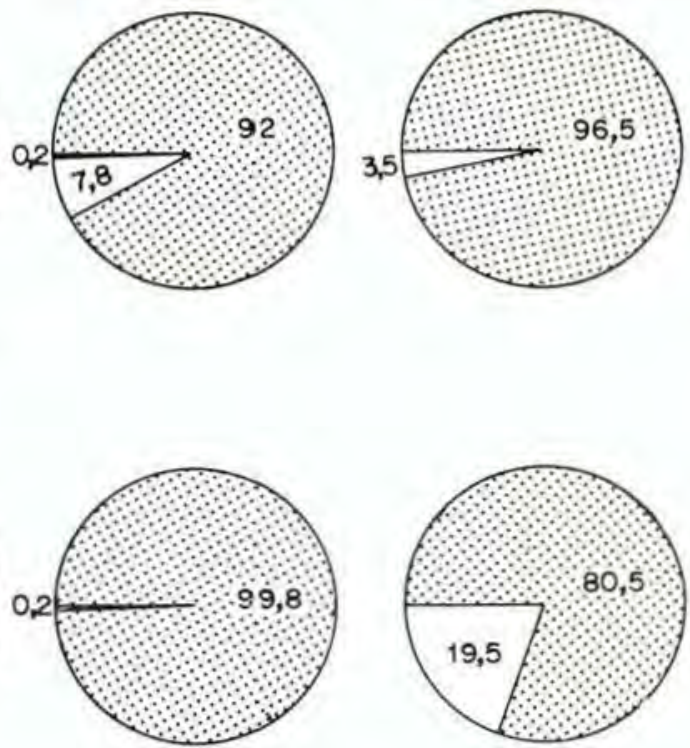

ㅁ. Notodiaptomus amazonicus

핌 $0,3 \%$ de $N$. cmazonicus $e$ $0,2 \%$ de $N$. coniferoides

Fig. 12 - Composição relativa em \% dos Copepoda, Calanoida em 5 lagos da região amazônica.

FEVE REIRO

L. Redondo

L. Castanho
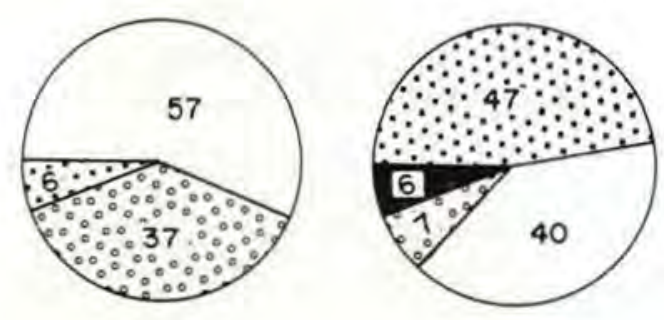

L. Jacaretinga

L. Cristalino

L. Tamonä-Mimim
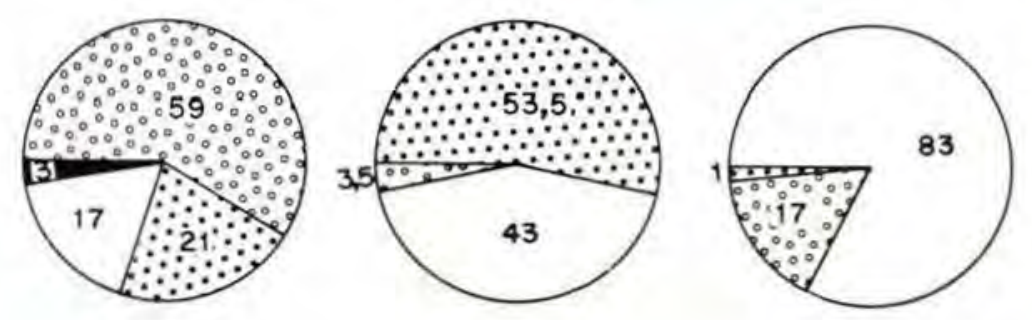

JULHO .
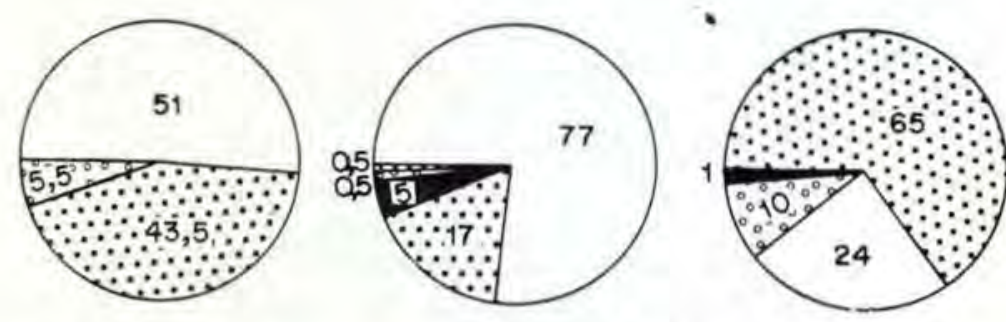

lermocyclops minutus Egoithona amazonica
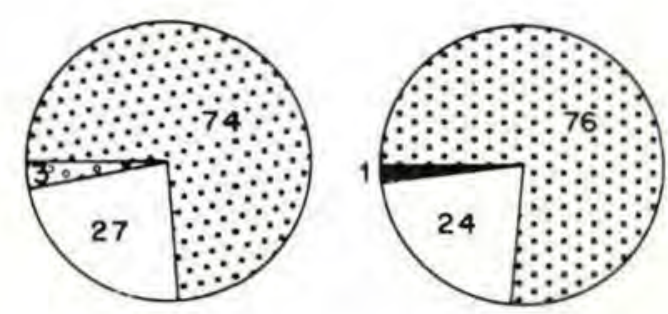

Copepodito

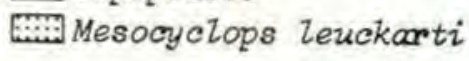

$\because$ Nouplius

Fig. 13 - Composição relativa em \% dos Copepoda, Cyclopoida em 5 lagos da regiâa amazônica, nos meses de fev./jul. 
na amostra, como o número esperado. O número esperado é dividido pelo número real de espécies encontradas.

A Tabela 15 apresenta a diversidade e a equitatividade da fauna de Cladocera calculadas para os lagos da Região Amazônica.

Os valores de equitatividade inferiores a 1 significam a existência de uma superposição de nichos, de acordo com o modelo de Mac Arthur (1957), pois, segundo sua fórmula, para que não haja uma superposição de nichos é necessário que o valor da equitatividade seja igual a 1 .

TABELA XV - Indice de diversidade de espécies (Shannon-Weaver) e equitatividade dos Cladocera, em 5 lagos da Região Amazônica

\begin{tabular}{|c|c|c|c|c|}
\hline \multirow{3}{*}{ LAGOS } & \multicolumn{4}{|c|}{ JULHO } \\
\hline & \multirow{2}{*}{$H^{\prime}$} & \multirow{2}{*}{$H_{\max }$} & \multirow{2}{*}{$\mathbf{E}=$} & $\mathbf{H}^{\prime}$ \\
\hline & & & & $H_{\max }$ \\
\hline Redondo & 0,50 & 2,00 & & 0,25 \\
\hline Castanho & 0.55 & 2.80 & & 0.19 \\
\hline Jacaretinga & 0,52 & 2,58 & & 0,20 \\
\hline Cristalino & 0,20 & 2,32 & & 0,08 \\
\hline \multirow[t]{2}{*}{ Tarumã-Mirim } & 0,20 & 2,58 & & 0.07 \\
\hline & \multicolumn{4}{|c|}{ FEVEREIRO } \\
\hline \multirow[t]{2}{*}{ L A GOS } & \multirow{2}{*}{$\mathbf{H}^{\prime}$} & \multirow{2}{*}{$H_{\max }$} & \multirow{2}{*}{$\mathbf{E}=$} & $\mathbf{H}^{\prime}$ \\
\hline & & & & $H_{\max }$ \\
\hline Redondo & 0.50 & 2,32 & & 0,21 \\
\hline Castanho & 0.57 & 2,58 & & 0,22 \\
\hline Jacaretinga & 0,43 & 2,80 & & 0,15 \\
\hline Cristalino & 0,33 & 2,32 & & 0.14 \\
\hline Tarumă-Mirim & 0.05 & 1,00 & & 0,05 \\
\hline
\end{tabular}

Os lagos de várzea - Redondo, Castanho e Jacaretinga - apresentam índices similares, sendo o mais alto encontrado no lago Castanho, com valor médio de 0,56 bits, enquanto que os de "água preta", Cristalino e Tarumãmirim, apresentam indices baixos, com valores médios de 0,26 bits e 0,12 bits, respectivamente.
Entre as várias estações consideradas, em cada lago, de maneira geral os índices foram semelhantes dentro de um mesmo lago, na época da vazante (fevereiro), porém, na época da cheia, a maioria dos lagos mostrou grandes flutuações (Tabela XVI).

TABELA XVI - indice de diversidade de espécies dos Cladocera nas Estações consideradas de 5 lagos da Regiāo Amazônica, nos meses de fevereiro e julho

\begin{tabular}{|c|c|c|c|}
\hline \multirow[b]{2}{*}{ Lagos } & \multirow[b]{2}{*}{ Estações } & \multirow{2}{*}{$\begin{array}{c}\text { Fevereiro } \\
\mathrm{H}^{\prime}\end{array}$} & \multirow{2}{*}{$\begin{array}{c}\text { Julho } \\
\mathrm{H}^{\prime}\end{array}$} \\
\hline & & & \\
\hline \multirow[t]{2}{*}{ Redondo } & I (centro) & 0.50 & 0.41 \\
\hline & II (margem) & - & 0.0 \\
\hline \multirow[t]{2}{*}{ Castanho } & I (centro) & 0,55 & 0,62 \\
\hline & II (margem) & 0,50 & 0,0 \\
\hline \multirow[t]{4}{*}{ Jacaretinga } & I (margem) & 0.63 & 0,60 \\
\hline & II (margem) & 0,60 & 0,0 \\
\hline & III (margem) & 0.53 & 0,55 \\
\hline & IV (centro) & 0,47 & 0,47 \\
\hline \multirow{3}{*}{ Cristalino } & I (margem) & 0,20 & 0,33 \\
\hline & II (centro) & 0.14 & 0,45 \\
\hline & III (margem) & 0,29 & 0,13 \\
\hline \multirow[t]{2}{*}{ Tarumā-Mirim } & $\begin{array}{l}\text { (+ próxima } \\
\text { do rio })\end{array}$ & 0,37 & 0.04 \\
\hline & II (margem) & 0,17 & 009 \\
\hline
\end{tabular}

A diversidade de espécies é maior nas estações localizadas, na região central dos lagos, do que nas localidades próximas às margens; porém o índice na porção central, muitas vezes, se apresenta mais baixo, face à distribuição irregular das diferentes espécies com algumas dominando, fortemente, sobre as outras.

A Figura 14 mostra o aspecto da distribuição das várias espécies de Cladocera nas estaçōes dos 5 lagos analisados nos meses de fevereiro e julho. 

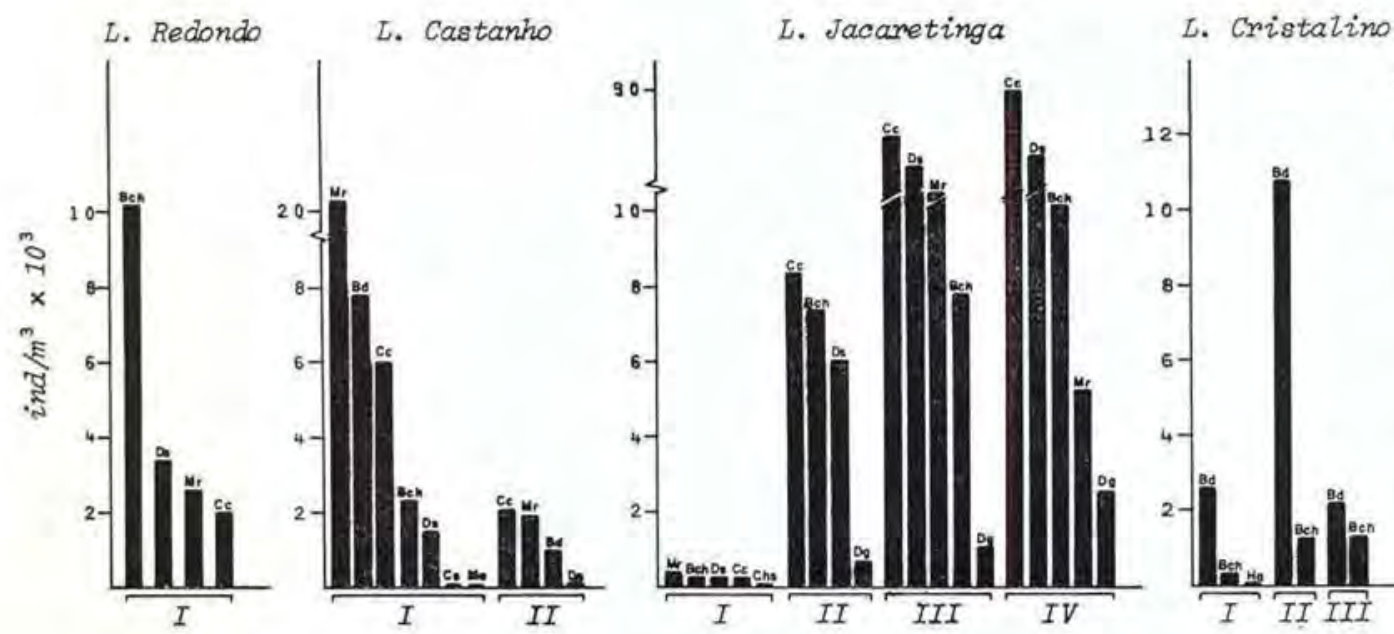

L. Tamonä-Mirim
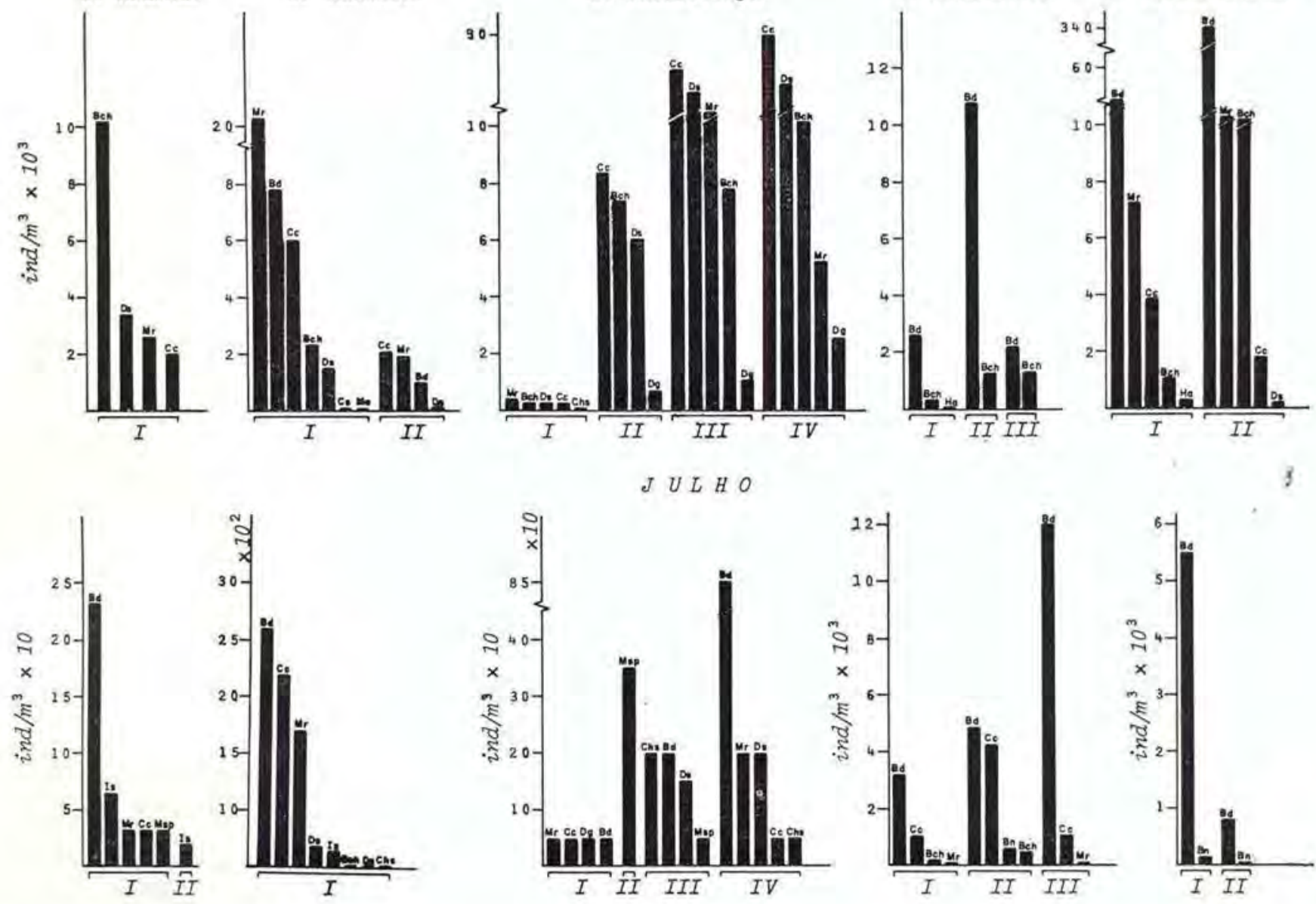

Fig. 14 - Distribuição e abundância das espécies de Cladocera nas estações consideradas de cinco lagos da Amazônia Central, nos meses de fevereiro e julho.

No lago Redondo, as duas estações analisadas no mês de julho, estação I localizada na região central do lago, apresentou 5 espécies com grande abundância de Bosminopsis deitersi, enquanto que na estação II, próxima à margem, onde há presença de plantas aquáticas, ocorreu somente uma única espécie, llyocryptus spinifer, comumente encontrada em associação com as plantas aquáticas. No lago Castanho, também a estação I, localizada na porção central, apresentou 7 espécies com a dominância de Moita reticulata, Bosminopsis deitersi e Ceriodaphnia cornuta. $\mathrm{Na}$ estação II, próxima à margem, não houve dominância marcante de uma espécie sobre as outras, ocorrendo de maneira similar 3 espécies: $\mathrm{Ce}$ - riodaphnia cornuta, Moina reticulata e Bosminopsis deitersi. O índice de diversidade nas duas estações foi respectivamente de: 055 bits e 0.50 bits.

No lago Jacaretinga, onde foram estudadas 4 estações, sendo: I, II e III de localização próxima às margens e a estação IV, na porção central, foi possivel observar que as estaçc̃es III e IV apresentaram composição e abundância semelhantes de Cladocera, havendo pequena diminuição na estação II e bastante acentuada na estação I. Nas estações II, III e IV, houve dominância das espécies Ceriodaphnia cornuta, Diaphanosoma sarsi, Moina reticulata e Bosmina chilensis. Na estação I, não foi observada dominância de espécies; portanto. 
o índice de diversidade foi aqui mais alto do que nas outras regiōes do lago, apresentando valor médio de 0.61 bits.

No lago Cristalino, as estaçôes I e II, localizadas próximas às margens, não diferiram da estação III, localizada na porção central do lago, quanto à diversidade e abundância das espécies. A que dominou, nas três estações, foi Bosminopsis deitersi. Não diferiu também o índice de diversidade obtido nas estaçōes consideradas, o qual teve os seguintes valores médios: 0.26 bits e 0.21 bits. No lago Tarumã-mirim, a estação I, localizada mais próxima ao rio Negro, apresentou 5 espécies de Cladocera com grande abundância de Bosminopsis deitersi, enquanto na estação II, localizada próxima à margem, 3 espécies foram dominantes: Bosminopsis deitersi, Moina reticulata e Bosmina chilensis. Seus índices de diversidade diferiram ligeiramente, sendo 0.37 bits na estação I e 0.17 na estação II. Este lago, no mês de julho, diferiu marcadamente do mês de fevereiro, quanto à diversidade das espécies. Nas estações I e II, ocorreram somente as duas espécies do gênero Bosminopsis: a deitersi e negrensis, com dominância de $B$. deitersi. Foram também mais baixos os índices no mês de julho, com valores de 0.04 bits e 0.09 bits, respectivamente, nas estações I e II, por causa da diminuição da riqueza de espécies.

Diversidade de espécies dos Rotifera A tabela XVII, apresenta a diversidade e a equitatividade da fauna de Rotifera, calculadas para os lagos da Região Amazônica. Para os Rotifera, os lagos de "água branca" não apresentaram índice de diversidade, como observado para os Cladocera. Na época da vazante, o lago Redondo apresentou o mais baixo índice ( 0.01 bits) face à pequena diversidade de espécies, seguido do lago Jacaretinga ( 0.18 bits). enquanto o Castanho apresentou índice maior ( 0.86 bits). Na época da cheia, houve mudança completa da situação, sendo que o lago que apresentou maior índice foi o Jacaretinga (1.02) e o menor, o Castanho (0,24 bits).

Os lagos de "água preta", Cristalino e Tarumã-mirim, apresentaram índices quase similares, sendo que no Cristalino o mais alto foi em julho $(0,60$ bits $)$ e no Tarumã-mirim em fevereiro $(0,60$ bits $)$.
TABELA XVIII - índice de diversidade de espécies (Shannon-Weaver) e equitatividade dos Rotifera, em 5 lagos da Regiâo Amazônica

\begin{tabular}{|c|c|c|c|c|}
\hline \multirow{3}{*}{ LAGOS } & \multicolumn{4}{|c|}{ FEVEREIRO } \\
\hline & \multirow{2}{*}{$\mathbf{H}^{\prime}$} & \multirow{2}{*}{ H inax } & \multirow{2}{*}{$\mathbf{E}=$} & $\boldsymbol{H}^{\prime}$ \\
\hline & & & & $H \max$ \\
\hline Redondo & 0,01 & 1,00 & & 0,01 \\
\hline Castanho & 0,86 & 4,16 & & 0,20 \\
\hline Jacaretinga & 0,18 & 2.80 & & 0,06 \\
\hline Crisialino & 0,48 & 2,32 & & 0,20 \\
\hline Tarumā-Mirim & $0, \mathrm{EO}$ & 3,00 & & 0,20 \\
\hline \multirow{3}{*}{ LAGOS } & \multicolumn{4}{|c|}{ JULHO } \\
\hline & \multirow{2}{*}{$\mathrm{H}^{\prime}$} & \multirow{2}{*}{$H_{\max }$} & \multirow{2}{*}{$\mathbf{E}=$} & $\mathbf{H}^{\prime}$ \\
\hline & & & & $H_{\max }$ \\
\hline Redondo & 0,86 & 4,08 & & 0.21 \\
\hline Castanho & 0,24 & 3,58 & & 0.06 \\
\hline Jacaretinga & 1,02 & 4,00 & & 0.25 \\
\hline Cristalino & 0,60 & 3.50 & & 0.17 \\
\hline Tarumã-Mirim & 0,53 & 3,70 & & 0,14 \\
\hline
\end{tabular}

$\mathrm{Na}$ análise feita para as estaçōes de cada lago, aqui consideradas, observa-se também para os Rotifera que no mês de fevereiro, quando os lagos são pouco profundos, dada a vazante, os índices, de maneira geral, foram semelhantes de uma estação para outra, ocorrendo o inverso, no mẽs de julho (época da cheia), quando a maioria dos lagos apresentou grandes flutuações (Tabela XVIII).

No lago Redondo, a estação I apresentou treze espécies de Rotifera, com grande dominância de Brachionus patulus, enquanto na estação II, ocorreram nove espécies, sendo a dominante Hexarthra intermedia brasiliensis (Figura 15). Os indices foram similares, nas estações I e II, com valores de 0.79 e 0.67 bits, no mês de julho. No lago Castanho, as estações I e II apresentaram grande dominância de espécies. Na estação I, ocorreram 17 espécies sendo: Keratella cochlearis e Brachionus dolabratus as mais dominantes, seguidas por Polyarthra sp., Brachionus falcatus, Filinia pejleri 
TABELA XVIII - Indice de diversidade de espécies dos Rotifera nas Estaçöes consideradas de 5 lagos da Região Amazônica, nos meses de fevereiro e julho

\begin{tabular}{|c|c|c|c|}
\hline \multirow{2}{*}{ Lagos } & \multirow{2}{*}{ Estaçôes } & \multirow{2}{*}{$\begin{array}{c}\text { Fevereiro } \\
\mathbf{H}^{\prime}\end{array}$} & \multirow{2}{*}{$\begin{array}{c}\text { Julho } \\
\text { H' }\end{array}$} \\
\hline & & & \\
\hline \multirow[t]{2}{*}{ Redondo } & I (centro) & 0,01 & 0,79 \\
\hline & II (margem) & - & 0.67 \\
\hline \multirow[t]{2}{*}{ Castanho } & I (centro) & 0,83 & 0,24 \\
\hline & II (margem) & 0,85 & 0,0 \\
\hline \multirow[t]{4}{*}{ Jacaretinga } & I (margem) & 0,28 & 1,03 \\
\hline & II (margem) & 0,04 & 0,42 \\
\hline & III (margem) & 0,17 & 0,91 \\
\hline & IV (centro) & 0,15 & 0,93 \\
\hline \multirow[t]{3}{*}{ Cristalino } & I (margem) & 0,46 & 0,60 \\
\hline & II (centro) & 0,48 & 0,38 \\
\hline & III (margem) & 0,36 & 0,48 \\
\hline \multirow[t]{2}{*}{ Tarumã-Mirim } & $\begin{array}{l}\text { I }+ \text { próxima } \\
\text { do rio })\end{array}$ & 0,50 & 0,52 \\
\hline & II (margem) & 0,64 & 0,33 \\
\hline
\end{tabular}

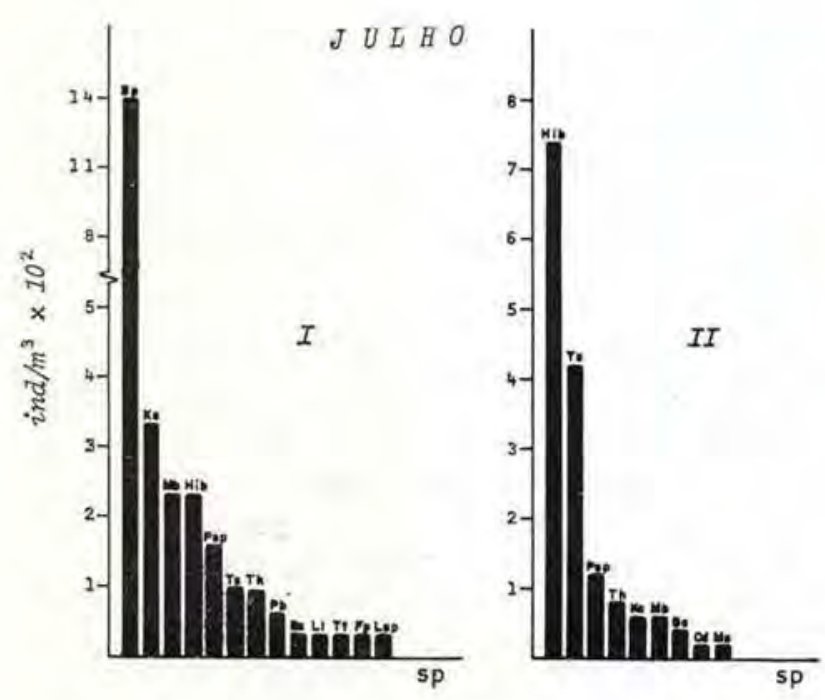

Fig. 15 - Distribuiçāo e abundância das espécies de Rotifera nas estações I e II do lago Redondo, no mês de julho. e Brachionus gessneri. As outras espécies (11) se apresentaram igualmente abundantes. Também na estação II, ocorreram 17 espécies, sendo que as mais abundantes foram: Brachionus falcatus, Brachionus dolabratus e Keratella cochlearis. No mês de julho, essas estações diferiram, apresentando declínio no número de espécies e na abundância total, chegando a desaparecer, totalmente, na estação II (Figura 16). Os maiores índices foram encontrados. nas estações I e II, no mês de fevereiro, com valores de 0.83 e 0.85 bits, respectivamente.

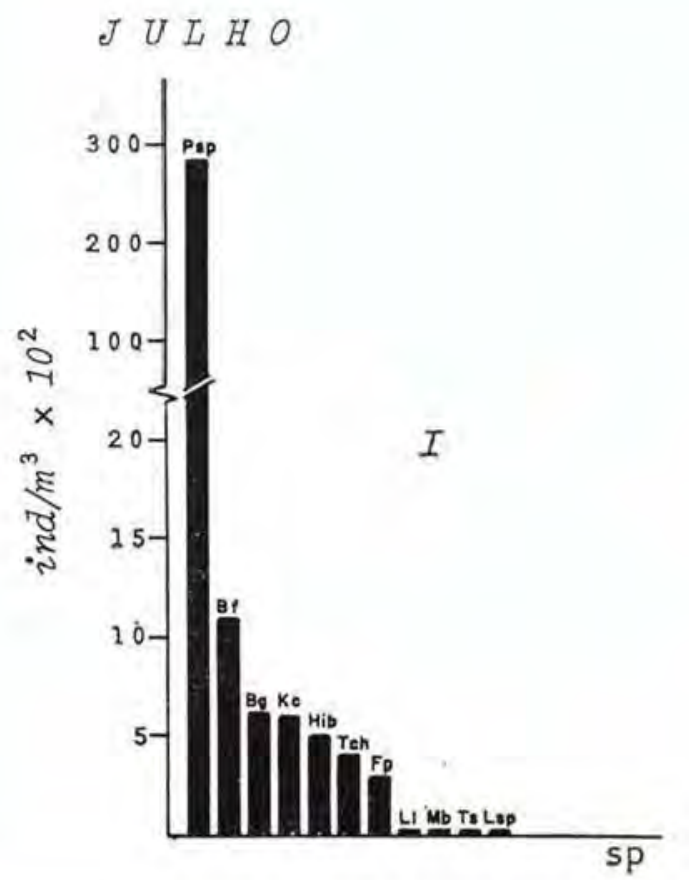

Fig. 16 - Distribuição e abundância das espésies de Rotifera nas estações I e II do lago Castanho, nos meses de fevereiro e julho.

Situação inversa à do lago anterior foi observada, no lago Jacaretinga, nos meses de fevereiro e julho (Figura 17). O número de espécies presentes, no mês de julho, foi bem maior do que no de fevereiro. Para as diversas estações analisadas (I, II, III e IV) no mês de fevereiro, houve dominância de uma única espécie de Rotifera, Brachionus falcatus. Os índices foram semelhantes nas estações I, III e IV, dife- 

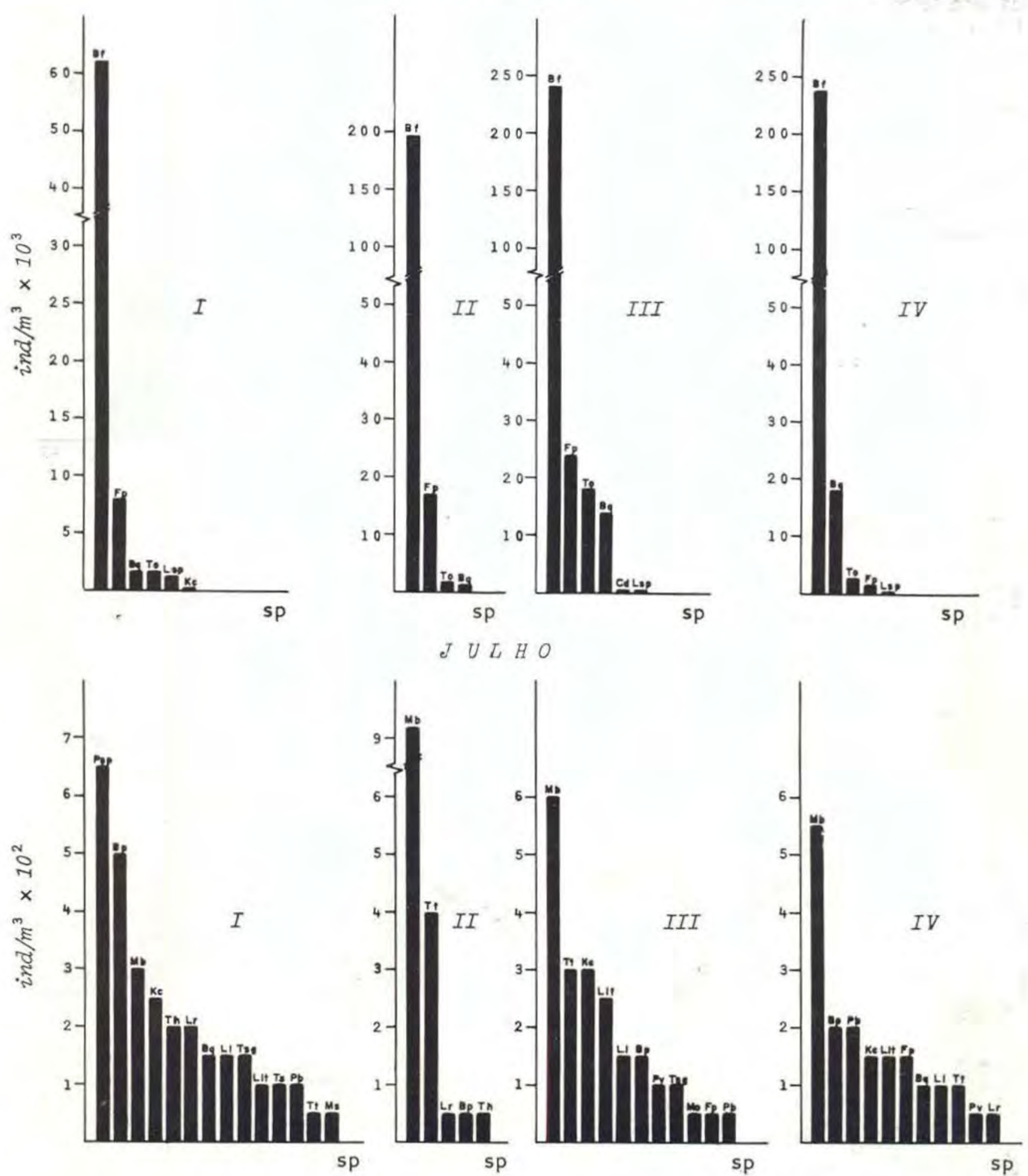

Fig. 17 - Distribuição e abundância das espécies de Rotifera nas estações I, II, III e IV do lago Jacaretinga, nos meses de fevereiro e julho. 
rindo na estação II, onde foi mais baixo $(0.04$ bits). Entretanto, no mês de julho houve mudança na dominância das espécies, diferindo de uma estação para outra. Na estação I, duas foram mais abundantes: Polyarthra sp.; e Brachionus patulus enquanto as outras 12 apresentaram igual abundância. Novamente, os índices foram semelhantes, nas estações I, II! e IV, sendo que o mais baixo foi obtido, na estação II (0,42 bits).

As estações analisadas, no lago Cristalino (estação I, II e III), não diferiram entre si, no mês de fevereiro, na dominância e na diversidade das espécies (Figura 18). As estações
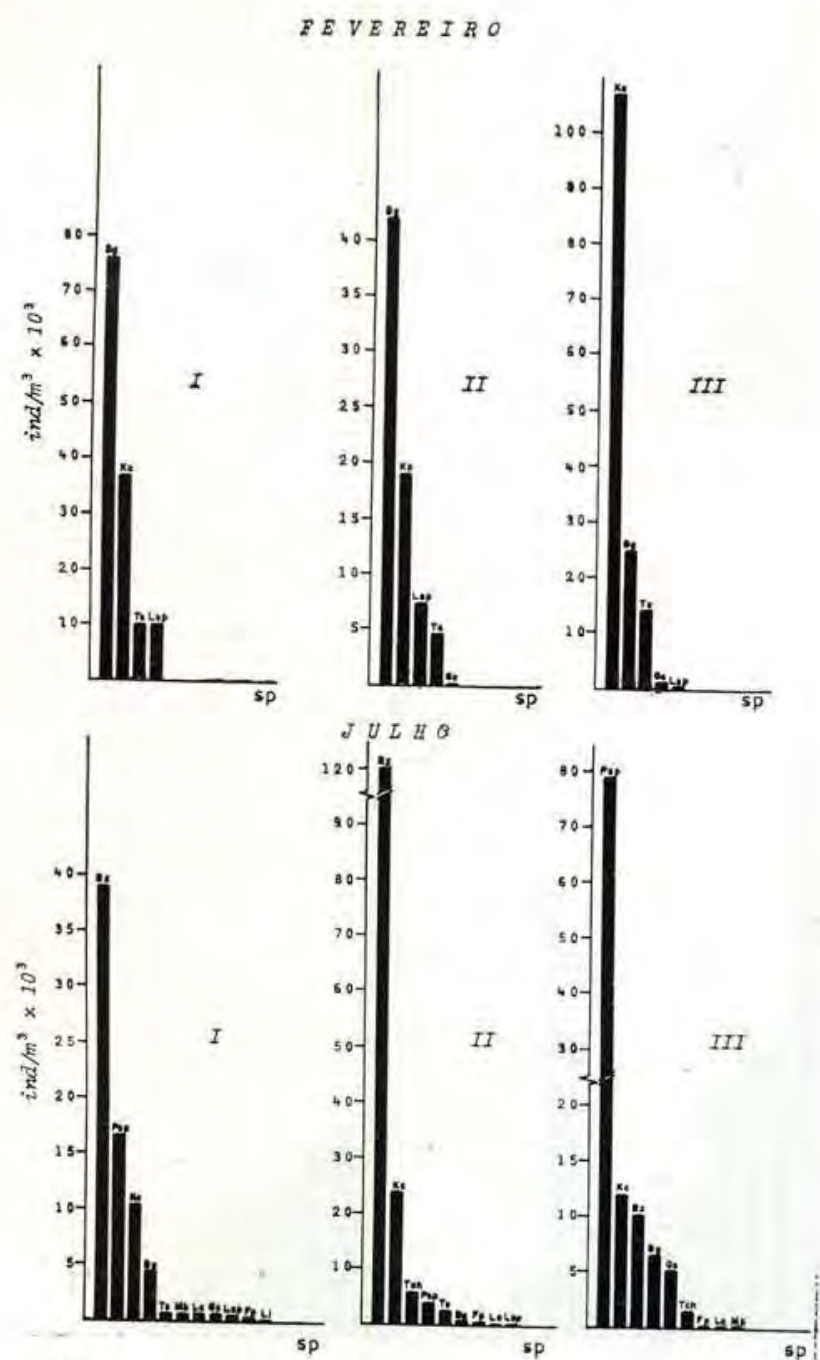

Fig. 18 - Distribuição e abundância das espécies de Rotifera nas estações I, II e III do lago Cristalino, nos meses de fevereiro e julho.
FEV E REIRO
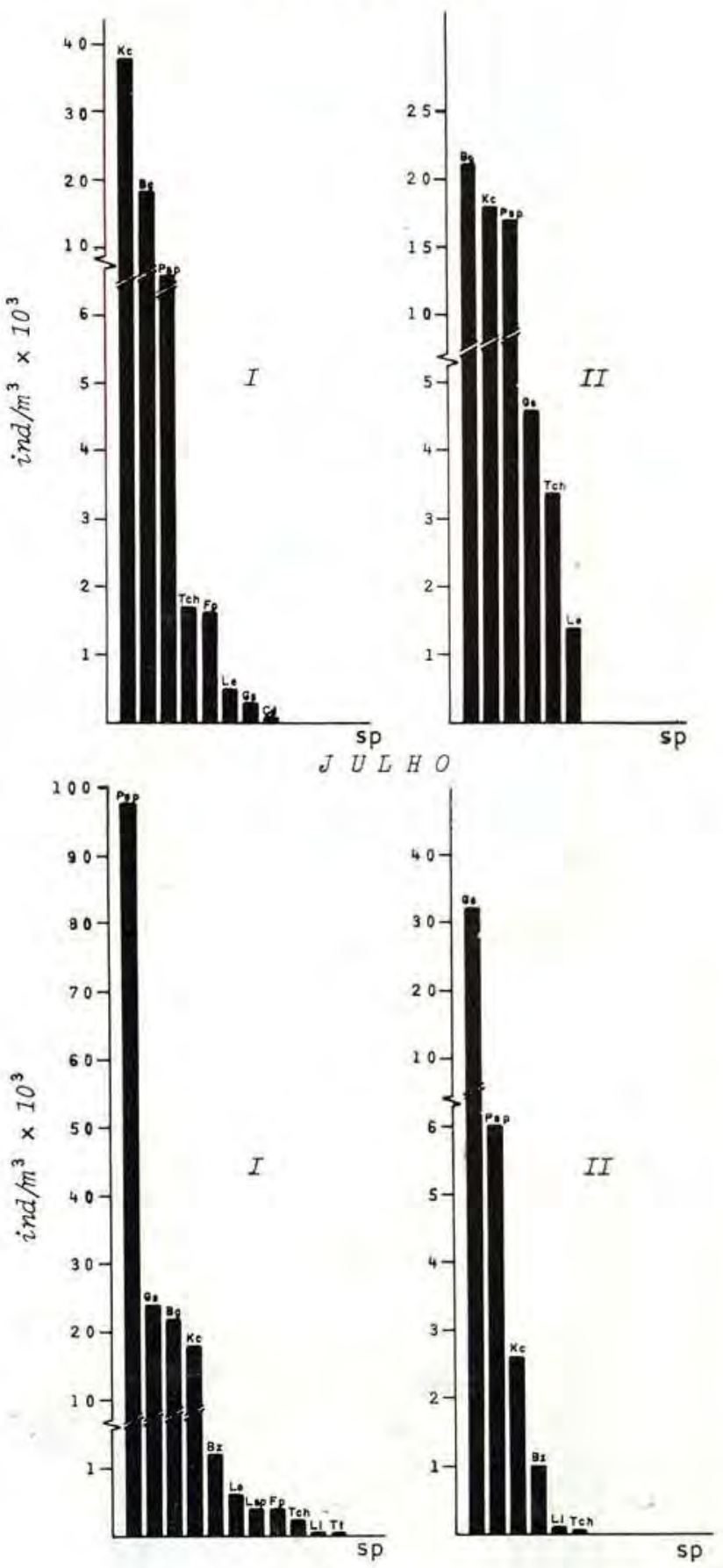

Fig. 19 - Distribuição e abundância das espécies de Rotifera nas estações I, II e III do lago Tarumã-Mirim. nos meses de fevereiro e julho.

I e II tiveram a mesma espécie dominante Brachionus gessneri; na estação II, Keratella cochlearis, foi mais abundante do que as outras ali presentes. Porém, no mês de julho, 
aumentou a diversidade das espécies nas três estações, entretanto, uma única espécie continuou sendo a dominante. Brachionus zanhiseri reductus foi mais abundante nas estações I e II e Polyarthra sp. na estação III. As outras espécies presentes, nas estaçōes consideradas. não diferiram quanto à diversidade e abundância. Nas estaçöes III, no mês de fevereiro, e a II, no mês de julho, ocorreram os menores indices, dada a alta dominância, apresentada por uma única espécie.

As duas estações do lago rarumã-mirim mostraram dominância das seguintes espécies: Keratella cochlearis, Brachionus gessneri e Polyarthra sp. As outras (5) na estaçāo I e (3) na estação II ocorreram, de maneira similar, no mês de fevereiro. Seus indices foram portanto bem próximos $(0,50$ e 0,64 bits; respectivamente, nas estações I e II.

Situação inversa observa-se, no mês de julho, quando nas estaçōes I e II, apresentaram uma única espécie dominante. Na estação I. a mais abundante foi Polyarthra sp. seguida por Gastropus stylifer, Brachionus gessneri e Keratella cochlearis; na estação II, a mais abundante foi Gastropus stylifer, seguida de Polyarthra sp. e Keratella cochlearis; as outras (3) foram muito abundantes. $O$ índice na estação I foi mais alto, em vista da maior riqueza de espécies.

Similaridade entre os vários lagos - O grau de similaridade, entre os 5 lagos, foi determinado, considerando-se todas as espécies de zooplancton e calculando-se o índice de similaridade, através da equação de Sörensen (1948), já referido, nos materiais e métodos.

Os indices de similaridade mais altos foram encontrados entre os lagos Cristalino e Tarumã-mirim, que são os que recebem a influência do rio Negro; e entre os lagos Redondo e Jacaretinga, que são de "várzea" (água branca) de localização próxima, apresentando quase as mesmas caracteristicas físicas, quimicas e morfológicas Tabela XIX.

$\mathrm{Na}$ Tabela XX, estão apresentadas as espécies de zooplancton comuns aos vários lagos, da Região Amazônica: dos Cladocera 5
TABELA XIX - Indice de similaridade (Sorensen) do zooplancton em 5 lagos da Região Amazônica

\begin{tabular}{l|llllll}
\cline { 2 - 6 } & $\begin{array}{l}\text { Cos- } \\
\text { tanho }\end{array}$ & $\begin{array}{c}\text { Re- } \\
\text { dondo }\end{array}$ & $\begin{array}{c}\text { Jaca- } \\
\text { retingo }\end{array}$ & $\begin{array}{c}\text { Cris- } \\
\text { talino }\end{array}$ & $\begin{array}{c}\text { Torumâ- } \\
\text {-Mirim }\end{array}$ \\
\hline Castanho & - & 67 & 68 & 52 & 43 \\
Redondo & - & 70 & 51 & 45 \\
Jacaretinga & & & - & 50 & 49 \\
Cristalino & & & & - & 78 \\
\hline
\end{tabular}

espécies, Bosmina chilensis, Bosminopsis deitersi, Ceriodaphnia cornuta, Macrotrix sp. e Moina reticulata, contribuiram para dar maior indice de similaridade, entre os lagos Redondo e Jacaretinga enquanto que para os lagos Cristalino e Tarumã-mirim foram as espécies: Bosmina chilensis, Bosminopsis deitersi, Holopedium amazonicum e Moina reticulata.

Dentre os Rotifera, 11 espécies foram comuns entre os dois lagos de várzea, Redondo e Jacaretinga: Brachionus sp. macracanthus, Conochiloides dossuarius, Filinia pejleri, Keratella cochlearis, Lecane leontina, Monostyla bulla, Mytilina ventralis, Testudinella mucronata haueriensis, Trichocerca s. grandis, Trichocerca similis e Polyarthra vulgaris. Já nos lagos de água preta, as espécies comuns foram: Brachionus gessneri, Brachionus z, reductus, Conochiloides dossuarius, Gastropus stylifer, Keratella cochlearis, Lecane leontına, Trichocerca chattoni, Trichocerca similis e Polyarthra $s p$.

Entre o grupo dos Copepoda, somente duas espécies, Oithona amazonica e Notodiaptomus amazonicus, foram comuns aos lagos Redondo e Jacaretinga, enquanto que para os lagos Cristalino e Tarumã-mirim, somente Oithona amazonica foi comum.

Os indices de similaridade, calculados para os grupos de Cladocera e Rotifera, não mostraram diferenças, de tal maneira que as associações de lagos, continuaram sendo as mesmas, quando considerados os índices a cada grupo isoladamente. 
TABELA XX - Espécies Comuns de Zooplancton em 5 lagos da Regiảo Amazônica

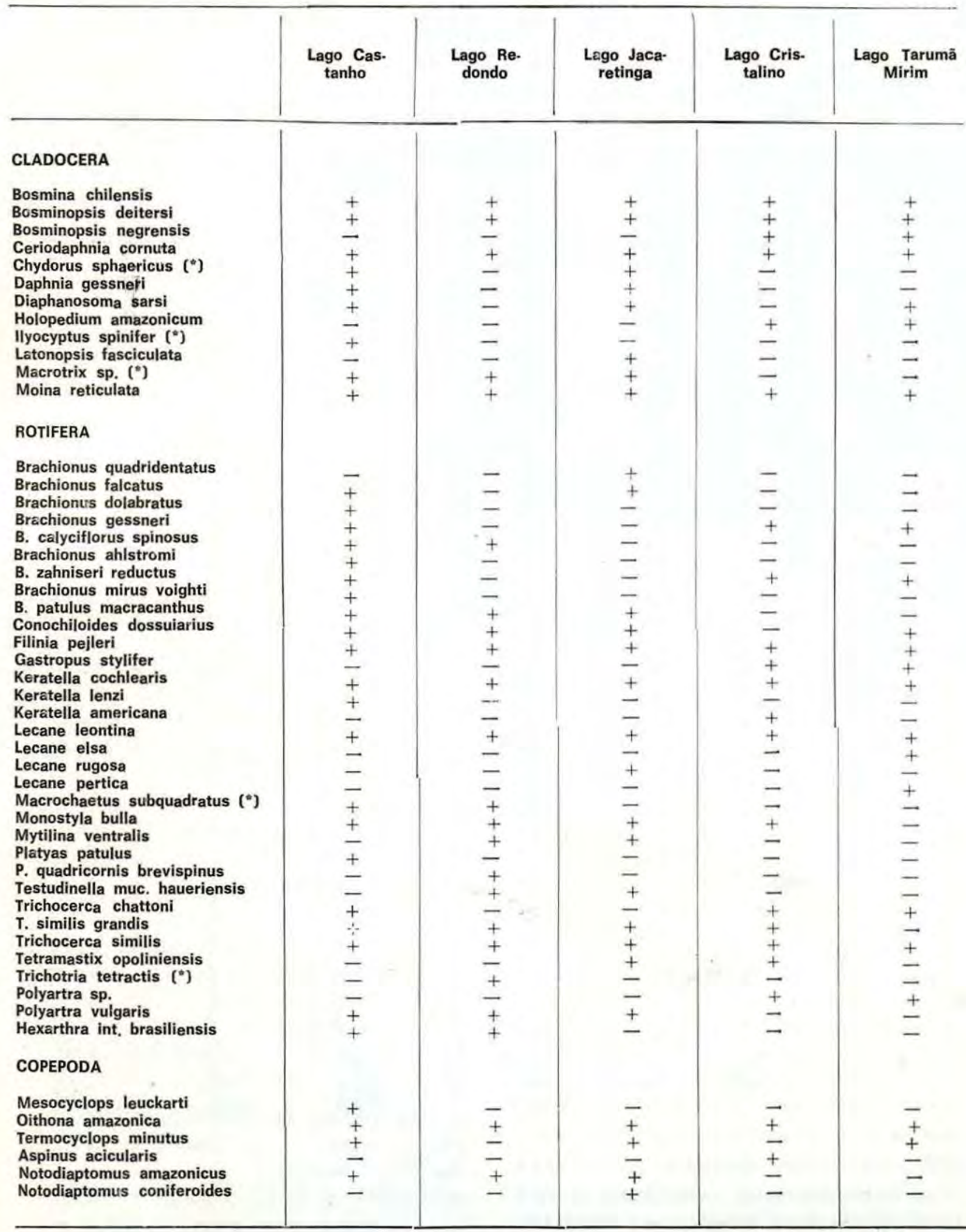

(*) - Espécies de cladoceros e rotíferos que năo pertencem ao plancton limnético. 


\section{DISCUSSÃo}

As propriedades físico-químicas e a natureza biológica, da maioria dos lagos da Ama. zônia Central, são fortemente atingidas pelas flutuaçōes do nível dos rios Solimōes e $\mathrm{Ne}$ gro, fenômeno este que se repete periodicamente, a cada ano. Esta variação rítmica do nível da água dos rios encontra explicação mais evidente, na distribuição irregular das precipitações e no degelo dos Andes e tem significado muito grande, no sistema de lagos da Amazônia, principalmente, na região de várzea. Nela, durante a enchente, grande quantidade de material alóctone é incorporada ao rio e, por ocasião do refluxo da água, formam-se lagos ricos de matéria orgânica, onde ocorre intenso desenvolvimento de organismos.

A composição e o "standing-stock" do zooplancton sofrem, assim, grandes altera. ções, durante o período de influxo e refluxo das águas. Nunca chega, porém a desaparecer totalmente, como foi verificado por Moghraby (1977) no Nilo Azul. Nesse rio, o autor verificou durante as enchentes, o desaparecimento total do zooplancton provocado pelas condiçōes desfavoráveis do ambiente dados o autmento da concentração de material em suspensão, a diminuição da penetração de luz e a eventual aderência das partículas em suspensăo aos organismos do zooplancton, impedindo sua respiração e dificultando o movimento das peças natatórias.

Nos lagos da Amazônia, realmente, na época da enchente, a densidade chega a diminuir cerca de três vezes a da época da vazante, face ao problema da diluição, porém o estoque de organismos continua, havendo, apenas, mudança na sua composição.

Os estudos de Brandorff \& Andrade (1978), realizados no lago Jacaretinga, mostram inicialmente, ligeiro aumento na densidade dos organismos, seguido por desaparecimento quase total, na época da inundação. Bonetto (1975) encontrou, no rio Paraná aumento no número de indivíduos sob condiçōes semelhantes, o que pode ser comparado ao pico encontrado por Brandorff \& Andrade (1978) após a entrada da água do rio.
Estas observações, entretanto, devem ser analisadas com muito cuidado pois não é so. mente um único fator, tal como o fluxo da água, que determina a natureza da abundância do plâncton, como foi considerado por Brook \& Woodward (1956) analisando alguns lagos de pequeno tamanho da Escócia. As condições de vida, desenvolvidas durante o afluxo da água, a capacidade adaptativa dos organismos a vários fatores ambientais e os ciclos reprodutivos das diferentes espécies, têm efeito muito grande sobre as flutuações da densidade dos organismos.

A tipificação dos rios da Amazônia, segun do Sioli (1965, 1967 e 1968) em rios de água branca, água preta e água clara, tem sido feita, baseando-se principalmente, nas características ópticas das águas. Naturalmente, es. sas águas possuem outros parâmetros físico quimicos característicos, fazendo com que sua composição zooplanctônica seja também variável.

Os lagos Jacaretinga, Redondo e Castanho, agrupados em um tipo (lagos de água branca ou de várzea), hidrologicamente são semelhantes, apresentando para a maioria dos parâmetros químicos, tais como: $\mathrm{pH}$, condutância específica, nutrientes inorgânicos (fósforo total e silicato reativo) e concentrações dos íons analisados $(\mathrm{Ca}++, \mathrm{Na}+, \mathrm{K}+\mathrm{e}$ $\mathrm{Mg+}+$ ) valores similares e mais altos, que os apresentado pelo outro grupo, que pertence ao tipo de lagos de água preta (Cristalino e Tarumâ-mirim) .

Os indices de similaridade calculados comprovam, também, a semelhança biológica entre os lagos de várzea e entre os de áqua preta.

A ocorrência restrita de determinadas espécies como: Bosminopsis negrensis (Cladocera) e Aspinus acicularis (Copepoda) em lagos de água preta (Cristalino e Tarumã-mirim), pode estar relacionada aos valores baixos de $\mathrm{pH}$ e baixas concentrações dos íons ali presentes; qualquer afirmaçāo, nesse sentido, necessita, porém, de estudos mais minuciosos. Sprules (1975) associa o declínio da diversidade de espécies, na comunidade zooplanctênica, com o pH, sendo que a maioria dos orga. 
nismos são eliminados em ambientes ácidos. permanecendo somente algumas espécies.

Os organismos zooplanctônicos de água doce, entretanto, são na maioria euriécios, apresentando largo espectro de tolerância a vários fatores ambientais, porém muitas espécies modificam esta euriecidade, na presença ou ausência de outros fatores. Os estudos de Edmondson (1944) com rotíferos sésseis mostram, claramente, a existência de mais de um fator, controlando a ocorrência de certas espécies de rotíferos a uma dada faixa de $\mathrm{pH}$.

A diversificaçăo em espécies, nos lagos estudados não apresenta grandes diferenças porém o número de espécies dominantes varia de lago para lago, o que acarreta indices de diversidade diferentes. Pennak (1957), em estudos feitos, nos vários lagos do Colorado, mostra que a diversidade de espécies se encontra relacionada mais com o tamanho dos lagos, do que propriamente com o seu estágiotrófico, não observando diferenças significativas no número de espécies, entre as águas oligotróficas e eutróficas.

Freqüentemente, observam-se grandes variações na composição de espécies e densidade do zooplâncton, entre diferentes localidades de um mesmo corpo de água. Este fato decorre, provavelmente, da interação de vários fatores tais como: ação do vento, deslocamentos das massas d'água, heterogeneidade ambiental quanto a parâmetros físico-químicos ou características morfométricas, apresentadas pelos corpos de água.

Nos lagos analisados, tanto o "standingstock" quanto os índices de diversidade variaram, conforme as estações consideradas. As estações localizadas na região litorânea e próxima à entrada do rio, sempre apresentaram menor densidade de organismos que aquelas situadas na parte central do lago. Isto provavelmente face às condiçōes desfavoráveis causadas pela entrada das águas do rio, trazendo grande quantidade de material em suspensão e pela própria correnteza. No lago Albert, Green (1971) encontrou resultados semelhantes, com menor densidade de organismos, na estação situada próximo à entrada do rio Nilo Vitória.
No lago Jacaretinga, grande diversidade de organismos foi observada, na região litorânea, provavelmente associada à presença de densa vegetação de macrófitas aquáticas, pois, segundo (Green, 1972a), as plantas aquáticas propiciam maior diversificação de habitat.

Na Amazônia, a dominância de espécies toi evidente em todos os lagos, em virtude da instabilidade de condições, ocasionada pelas enchentes regulares.

Segundo Goulden (1969), os ecossistemas imaturos ou com distúrbios são geralmente caracterizados pelas associações zooplanctônicas de baixa diversidade, que apresentam uma espécie mais abundante do que todas as outras. Sendo o ambiente instável, as espécies denominadas de "generalista", ou seja fisiológica e ecologicamente bem adaptadas às mudanças imprevisiveis do ambiente, dominam a comunidade zooplanctônica e, como possuem amplo requerimento de nicho ecológico, não permitem o estabelecimento de outras no ambiente, diminuindo-Ihes assim a diversidade.

Quando o ambiente se torna mais favorável, as espécies denominadas de "especialistas" substituem as "generalistas": neste caso, tais espécies permitem a coexistência de outras, aumentando, assim, a diversidade.

Dos grupos analisados, os Rotifera apresentaram maior diversidade de espécies, por serem mais oportunistas, segundo Allan (1976), seguidos pelos Cladocera e Copepoda, respectivamente. Este fato, está diretamente relacionado à biologia destes organismos. Tanto os Rotifera como os Cladocera, têm ciclos de vida curtos com muitas geraçōes por ano e de. senvolvem grandes populações transitórias. Ambas apresentam reprodução partenogenética, porém, em condições desfavoráveis, segundo alguns autores, passam a reproduzir-se sexualmente (Hutchinson, 1967). Outros organismos planctônicos, tais como os copepodos, apresentam ciclos de vida mais longos, com poucas geraçōes por ano, diferindo marcadamente de rotíferos e cladoceros, pela sexualidade obriatória. Segundo Mac Arthur (1972, Apud, Allan, 1976), os ambientes instáveis favorecem os organismos oportunistas que apresentam altas taxas de crescimento, permitindo 
o desenvolvimento de inúmeras espécies. Os lagos da Amazônia Central são ambientes que sofrem os distúrbios periódicos das inunda. ções favorecendo, principalmente, os grupos dos rotíferos e cladóceros.

Os índices de diversidade de espécies nos lagos estudados, demonstra que eles não foram fortemente atingidos pelas perturbaçōes causadas pelas enchentes. Este comportamento foi observado para Cladocera as quais não apresentaram diversificaçōes. Os lagos de várzea apresentaram índices similares, sendo mais altos do que os dos lagos de terra firme: estes últimos apresentaram, além de menor diversidade de espécies do que os dos lagos de várzea, baixa equitatividade, o que justifica índices mais baixos.

Estes indices de diversidade para os Cladoceras, de modo geral, foram baixos, quando comparados aos encontrados por Green (1972). nos lagos do Suiámissu. Para os Rotifera, não foi observado o mesmo padrão encontrado para Cladocera, pois grandes variações ocorreram nos índices, principalmente, nos lagos de várzea. A baixa equitatividade foi, provavelmente, o componente que mais atingiu os índices, pois quanto à riqueza de espécies, excetuando o lago Redondo, no mês de fevereiro que não teve variação. Estes índices, com parados aos de Schaden (1976) dos lagos Jacaretinga e Castanho, apresentaram valores diferentes, porém isto se deve, de um lado, à metodologia empregada pelos autores para a amostragem do material, no campo e no laboratório, para fins de contagem. Por outro lado a composição zooplanctônica sofre mudanças periódicas sendo que os índices variam de uma época para outra, como pôde ser observado. no presente trabalho, não servindo, portanto, para caracterizar os lagos, quando os estudos são feitos em épocas diferentes.

Em virtude da distribuição agregada dos organismos zooplanctônicos, os índices podem variar de um local para outro, dentro do mesmo lago, dependendo das características morfométricas, ocorrência de tipos de vegetação aquática e flutuação do nível de água. Green (1972) encontrou maior indice para a fauna de
Rotifera, na região litorânea do lago Crescent, fortemente influenciada por macrófitas aquáticas.

Nos lagos da Amazônia, durante a época em que o nivel da água permaneceu baixo, não houve variação nos indices, nas diferentes partes consideradas do lago, porém, no mês de julho, quando o nível da água se eleva, as estações próximas à margem, apresentam indices menores que a região de águas abertas. A baixa diversidade e mesmo a ausência de organismos planctônicos, nestas estações, pode estar relacionada com a baixa concentração de oxigênio. Outro fator provável é o refluxo das águas, carregando estes organismos, através das diversas saídas do lago.

\section{Agradecimentos}

Agradecemos ao Departamento de Ciên cias Biológicas da Universidade Federal de São Carlos, a Divisāo Peixe/Pesca do Instituto $\mathrm{Na}$ cional de Pesquisas da Amazônia e a Profa. Dra. Tocaya M. Tundisi, pelo apoio e facilidades concedidas para o bom desempenho deste trabalho.

\section{SUMMARY}

A study of the species composition, satnding-stock and diversity of the zooplancton groups Rotifera, Cladocera and Copepoda, was conducted in five lakes in the Central Amazonian region. The lakes present distinct physical, chemical and biological parameters which allows for distinguishing two groups: On the first group, caracterized by the lakes which present greater concentration of ions, greater availability of nutrients, and greater diversity of zooplancton species are the "várzea" lakes, Castanho, Redondo and Jacaretinga. On the second group, caracterized by the lakes which present low concentrations of ions, few nutrients, and a low diversity of zooplancton species are the "terrafirme" lakes, Cristalino and tarumā-Mirim.

The structure of the zooplancton comunities in Amazonian lakes is periodically altered by the inundation of the rivers.

\section{BIBLIOGRAFIA}

Allan, J. DAvid

1976 - Life history patterns in zooplancton. The American Naturalist, 110 n. 971, 165-180

BONeTTO, A.A.

1975 - Hidrologic regime of the Paraná River and influence on ecosystems. In: Hasler, D. Coupling of land and water systems. Sprin. ger Verlag, Berlin 175-197. 
BrandorfF, G.O

1972 - Ein Beitrag zue Calennidenfauna (Crusta. cea, Copepoda) des Amazonas gebietes, mit einen Uberblick Uber die Diaptomem (Crustacea, Copepoda) Sudamerikas. Diflomarbeit, Kiel.

1973 - Neue Freilebende Calanoide Copepoden (Crustacea) aus dem Amazonasgebiet. Amazoniana, 4(2) : 205-218.

1976 - A new species of Bosmonopsis (Crustacea Cladocera) Bosminopsis negrensis from the rio Negro. Acta Amazonica, 6:109-114.

1977 - Untersuchungen zur Populationsdynamik des Crustaceanplanktons im Tropischen lago Castanho (Amazonas, Brasilien). Dissert. zur Erlangung des Doktograaes. Kiel, $108 \mathrm{p}$.

BANDORFF, G.O. \& ANDRADE, E.R.

1978 - The relationship between the water level of the Amazon River and the fate of the zooplankton population in lago Jacaretinga. a várzea lake in the Central Amazon. Studies on Neot. Fauna and Enviromment, $13: 63-70$.

Brook, A.J. \& WOODWARD, W.B.

1956 - Some observacions on the effects of water inflow and outflow on the plankton of small lakes, J. Anim, ecol., $25: 22-35$.

BURGIS, M.J.

1973 - Observacions on the Cladocera of lake George, Uganda. J. Zol., Lond., 170:339-349

Cipolli, M.N. \& DE Carvalho, M.A.J.

1973 - Levantamento de Calanoida e Cyclopcida (Copepoda, Crustacea) das águas da re gião do Guamá, Capim e Tocantins, com nota sobre a fauna acompanhante. Papéis Avulsos Zool., São Paulo, 27(8) : 95-110.

DADAY, E, VON

1902 - Beiträge zur Kenntnis der SusswassweMikrofauna von Chile. Termeszet Füz, 25: 436-447.

DICE, L.R.

1968 - Natural Communities, Ann. Arbor, Univ. Michigan Press, 547 p.

EDMONDSON, W.T.

1944 - Ecological studies of sessile Rotatoria. Part 1. Factores affecting distribution. Ecol. Monogr., $14: 31-36$.

1959 - Fresh water biology, 2nd editin. John Wiley \& Sons Inc. 1248 p.

Golterman, H.L.

1969 - Methods for chemical analysis of fresh water. I.B.P. Handbook n.० 8 Oxford \& Edinberg, Blackwell Scientific Publications. $166 \mathrm{p}$.

GOULDEN, C.E.

1969 - Temporal changes in diversity. Broakhaven Synposia in Biology, $22: 96-102$.
GrASSHOFF, K.

1964 - Nitrate in salt and potable water, Kiel Me. resforschung, 20(1): 5-11.

GREEN, J.

1971 - Associations of Cladocera in the zooplankton of tre lakes sources of the White Nile. z. Zool., 165 ; 373-414.

$1972 a$ - Freshwater ecology in the Mato Grosso. Central Brasil II. Associations of Cladocera in meander lakes of the rio Suiá Missú. J. Nat. Hist., $6: 215-227$

$1972 \mathrm{~b}$ - Freshwater ecologi in the Mato Grosso, Central Brazil III. Associations of Rotifera in meander lakes of the rio Suiá Missú. J. Nat. Hist., $6: 229-241$.

1976 - Changes in the zooplankton of lakes Mutanda. Bunyonyi and Mulehe (Uganda). Fresh. Biol., $6: 433-436$.

HARDING, J.P.

1957 - Crustacea: Cladocera. Inst. Roy. Science. Nat. Belgique. Explor. Hydrobiol, Lac Tanganika (1946-1947). Result. Scient. 3(6) : 54-89.

HERBST, H.V

1967 - Copepoda und Cladocera (Crustacea) aus Sudamerika. Gewass. Abwass, 44/45: 96-108

Hutchinson, G.E.

1967 - A treatise on limnology., 2: Introduction to lake Biology and the Limnoplamkton. New York, John Willey \& Sons, Inc. $1115 p$

JUNK, W.

1973 - Investigations on the ecology and Production-Biology of the "Floating Meadows" (Paspalo-Echinochloetum) on the middle Amazon. Part II. The Aquatic fauna in the root zone of floating vegetation. Amazoniana, $4(1): 9-102$.

Koste, W.

1972 - Rotatorien aus Gewassern Amazonions. Amazoniana, $3: 258-505$.

1974 - Rotatorien aus einem Ufersee des Unteren rio Tapajos, dem lago Paroni (Amazonien). Gewäss. Abwäss, $53 / 54:$ 43-68.

LLOYD \& GHELARD

1964 - A table for calculating the "equitability" component of species diversity. J. Animal Ecology, $33: 217-225$.

MAC ARTHUR \& MAC ARTHUR

1957 - Onbird species diversity. Ecology, 42 : 594-598

MARGALEF, R.

1974 - Ecologia. Edições Omega, S.A., Barcelo. na, $951 \mathrm{p}$.

MArLier, G

1965 - Etude sur les lacs de l'Amazonie centrale. Cadernos da Amazonia, $5: 51 \mathrm{p}$. 
MARSH, C.D.

1913 - Report on the freshwater Copepoda from Panama, with descriptions of new species. Smiths. Miscell, Coll., 61(3) : 1-31

Moghraby, A.I. EI

1977 - A study on diapause of zooplanktor in tropical river-The Blue Nile. Freshwater Biology, $7:$ 207-212.

OLIVIER, S.R.

1962 - Rotiferos planctônicos de Argentina, Revista del Museo de la Plata. 8(63) : 177-260.

PENNAK, R.W.

1953 - Freshwater Invertebrates of the United States. New York, Ronald Press Co., 769 p.

1957 - Species composition of limnetic zooplankton communities. Limnol. Oceanogr. 2: 222-232.

Prelou, E.C.

1966 - The measurement of diversity in different types of biological collection. J. Theoret. Biol., $13: 131-144$.

RICHARD, J.

1897 - Entomostraces de l'Amerique du Sud rearillis pae M.M.U. Deiters, H. von Therinh, G.W. Muiler et C,O. Poppe. Mém. Soc. Zool., France, 10(298) : 264-268.

SANTOS, A.

1978 - Ácido húmico e ácido fúlvico no sedimento de dois lagos na Amazônia Central (lago Caiaué e lago Jacaretinga). Dessert. de MsC. Săo Carlos, 138 p.

SARS, G.O.

1901 - Contributions to the knowlwdge of the freshwater Entomostraca of South America as shown by artificial hatching from dried material. Part II. Copepoda-Ostracoda. Archiv for Mathematik of Naturvidenskab B., 25(1) : 1-52.

SCHMiDT, G.W.

1973 - Primary production of phytoplankton in the three types of Amazonian waters. III. Primary productivity of phytoplankton in a tropical $\mathrm{fl}$ floodplain lake in central amazo. nia, lago do Castanho. Amazonas, Brazil. Amazoniana, 4(4) : 319-404.
SCHADEN, $R$.

1976 - Faunistisch - okologische Untersuchungen Planktischer Radertiere Amazoniens mit einem Uberblick uber die Kenntnisse Sudamerikanischer. Arten und Unterarter. Tese de doutorado. Univ. Kiel.

SHANnon, C.E. \& Weaver, W.

1949 - The mathematical theory of communication. University of Illinois. $125 \mathrm{p}$.

SIOLI, H

1965 - A limnologia e sua importância em pesquisas da Amazônia. Amazoniana, 1[1] 11-35.

1967 - Studies in Amazonian waters. Atas Simp. Biota Amazonica, 3:9-50.

1968 - Principal biotopes of primary production in the waters of Amazonia. The International Society for Tropical Ecology. 592-600 p.

SORENSEN, $T$.

1948 - A method of establishing groups of equal amplitude in plant sociology based on similarity of species content and its application to analyse of the vegetation of Danish commons. Biol. Skr., 5, $34 \mathrm{p}$

Sprules, W.G.

1975 - Factors affecting the structure of limnetic crustacean zooplankton communities in central Ontario lakes. Verh. Internat. Verein. Linmology, $19 ; 635-643$.

STRICKLAND, J.D.H. \& PARSONS, T.R.

1965 - A manual of sea water analyses. Otawa Risheries Research Board of Canada.

Thomasson, $\mathrm{K}$.

1953 - Studien uber das Sudamerikanische Subwasswe-Plankton. 2 Zur Kenntnis des Sudamerikanischen Zooolankton. Ark. Zool. 6: 189-194

(Aceito para publicaçāo em $3 / 9^{/ 79}$ ) 